\title{
Analysis of Potential Leakage Pathways and Mineralization within Caprocks for Geologic Storage of $\mathrm{CO}_{2}$
}

Final Scientific/Technical Report

Reporting Period Start Date: October 1, 2009

Reporting Period End Date: November 30, 2012

Principal Author(s) James P. Evans

May, 2013

DOE Award Number DE- FE0001786

Department of Geology

Utah State University

Logan, UT 84322-4505 
"This report was prepared as an account of work sponsored by an agency of the United States Government. Neither the United States Government nor any agency thereof, nor any of their employees, makes any warranty, express or implied, or assumes any legal liability or responsibility for the accuracy, completeness, or usefulness of any information, apparatus, product, or process disclosed, or represents that its use would not infringe privately owned rights. Reference herein to any specific commercial product, process, or service by trade name, trademark, manufacturer, or otherwise does not necessarily constitute or imply its endorsement, recommendation, or favoring by the United States Government or any agency thereof. The views and opinions of authors expressed herein do not necessarily state or reflect those of the United States Government or any agency thereof." 


\section{EXECUTIVE SUMMARY}

We used a multifaceted approach to investigate the nature of caprocks above, and the interface between, reservoir-quality rocks that might serve as targets for carbon storage. Fieldwork in southeastern Utah examined the regional- to $\mathrm{m}$-scale nature of faults and fractures across the sedimentiological interfaces. We also used microscopic analyses and mechanical modeling to examine the question as to how the contacts between units interact, and how fractures may allow fluids to move from reservoirs to caprock.

Regional-scale analyses using ASTER data enabled us to identify location of alteration, which led to site-specific studies of deformation and fluid flow. In the Jurassic Carmel Formation, a seal for the Navajo Sandstone, we evaluated mesoscale variability in fracture density and morphology and variability in elastic moduli in the Jurassic Carmel Formation, a proposed seal to the underlying Navajo Sandstone for $\mathrm{CO}_{2}$ geosequestration. By combining mechano-stratigraphic outcrop observations with elastic moduli derived from wireline log data, we characterize the variability in fracture pattern and morphology with the observed variability in rock strength within this heterolithic top seal.

Outcrop inventories of discontinuities show fracture densities decrease as bed thickness increases and fracture propagation morphology across lithologic interfaces vary with changing interface type. Dynamic elastic moduli, calculated from wireline log data, show that Young's modulus varies by up to $40 \mathrm{GPa}$ across depositional interfaces, and by an average of $3 \mathrm{GPa}$ across the reservoir/seal interface. We expect that the mesoscale changes in rock strength will affect the distributions of localized stress and thereby influence fracture propagation and fluid flow behavior within the seal. These data provide a means to closely tie outcrop observations to those derived from subsurface data and estimates of subsurface rock strength.

We also studied damage zones associated normal faults in the Permian Cedar Mesa Sandstone, southeastern Utah. These faults are characterized by a single slip surfaces and damage zones containing deformation bands, veins, and joints. Field observations include crosscutting relationships, permeability increase, rock strength decrease, and ultraviolet light induced mineral fluorescence within the damage zone. These field observations combined with the interpreted paragenetic sequence from petrographic analysis, suggests a deformation history of reactivation and several mineralization events in an otherwise low-permeability fault. All deformation bands and veins fluoresce under ultraviolet light, suggesting connectivity and a shared mineralization history. Pre-existing deformation features act as loci for younger deformation and mineralization events, this fault and its damage zone illustrate the importance of the fault damage zone to subsurface fluid flow. We model a simplified stress history in order to understand the importance of rock properties and magnitude of tectonic stress on the deformation features within the damage zone. The moderate confining pressures, possible variations in pore pressure, and the porous, fine-grained nature of the Cedar Mesa Sandstone results in a fault damage zone characterized by enhanced permeability, subsurface fluid flow, and mineralization.

Structural setting greatly influences fracture spacing and orientation. Three structural settings were examined and include fault proximity, a fold limb of constant dip, and a setting proximal to the syncline hinge. Fracture spacing and dominant fracture orientation vary at each setting and distinctions between regional and local paleo-stress directions can be made. Joints on the fold limb strike normal to the fold axis/bedding and are interpreted to be sub-parallel to the maximum regional paleo-stress direction as there is no fold related strain. Joints proximal to faults and the syncline hinge may have formed under local stress conditions associated with folding and faulting, and in some cases, are perpendicular to the maximum regional paleo-stress direction.

Macroscale analyses of the Iron Wash fault, which cuts most of the stratigraphy of the reservoirseal analogs, reveals that seal bypass occurs along faults with mixed lithologic composition. While portions of the fault may be effective seals, when modeled as a whole the fault zone cannot support a high $\mathrm{CO}_{2}$ column. We adapted oil-field methods to calculate column heights and sealing capacities.

Examination of the burial and tectonic histories of the rocks, coupled with field- and micro-scale studies, allow us to examine the potential for seal failure using basic rock mechanics failure analyses. These studies reveal that the sealing lithologies experienced multiple episodes of deformation that resulted in numerous fractures and small faults. In a stress state based on burial history and overburden loads, we show that most of the seals could fail with normal to slightly excess pore pressures. 


\section{Analysis of Potential Leakage Pathways and Mineralization within Caprocks for Geologic Storage of $\mathrm{CO}_{2}$}

The Utah State University (USU) Geology Department conducted research and training efforts under DOE project DE - FC26 - 0xNT4 FE0001786 to examine the nature and controls of caprock integrity on field-based analogs for $\mathrm{CO}_{2}$ sequestration systems. This effort analyzed the integrity of caprock in exhumed (unearthed) analogs of $\mathrm{CO}_{2}$ flow systems in order to determine the processes of $\mathrm{CO}_{2}$ flow in leakage scenarios resulting from the presence of fractures or faults. Suitable geologic storage formations typically possess the ability to retain injected $\mathrm{CO}_{2}$ due to the presence of low-permeability confining layers (caprock) above the injected reservoir, impeding upward $\mathrm{CO}_{2}$ movement into shallower aquifers. Our results will help constrain risk-based assessments and provide further insight into the design of sequestration systems. Fieldwork was conducted at four separate field sites at which USU has worked in the past. These studies included:

1. Examination of the geologic, stratigraphic, and geomechanical setting of faults and fractures that have affected past and present $\mathrm{CO}_{2}$ flow in exhumed analogs in the Utah portion of the Colorado Plateau, where vast amounts of naturally sourced $\mathrm{CO}_{2}$ have flowed through rocks. We examined the results of $\mathrm{CO}_{2}$ flow, the impact of caprock as a seal, the effects that fractures and faults have had on this flow, and patterns of carbonate mineralization in the caprock. We determined the conditions that led to development of the fracture systems or faults, their impact on $\mathrm{CO}_{2}$ flow through the caprock, and evaluate the nature of mineralization within the caprock that may have reestablished an effective seal.

2. Quantification of the potential impacts on storage through a series of rock core studies, and laboratory observational studies of the deformed and altered rocks.

3. Integrated and comprehensive studies for students ranging from undergraduate through PhD-level who are well versed in the geologic analysis and modeling of $\mathrm{CO}_{2}$ flow in sequestration environments.

4. Through field and laboratory studies, we quantified deformation processes that affect the transmissivity of fractures in argillaceous mudstones, which are the major target for locations of $\mathrm{CO}_{2}$ storage (Bachu 2008). 


\section{Approach and Scope of Work}

Phase 1 of this project was a short-term preparation and planning effort. In Phase 2 of this work, we performed a survey of the region of interest, and identified sites with clear analog aspects to the storage/sequestration issue (Barton, 2011; Petrie et al., 2013). In Phase 3, we used detailed field and core-based studies of fractured and faulted rocks, where evidence for $\mathrm{CO}_{2}$ flow was abundant, to evaluate how $\mathrm{CO}_{2}$ migration occurred across cap rock (Barton, 2011; Petrie et al., 2012; Petrie et al., submitted). We also examined the nature of mineralization within the caprock, where carbonate minerals appeared to have formed along fractures and bed planes and collected field samples for subsequent laboratory analyses. Phase 3 also consisted of laboratory-based studies of the rocks, focusing on the small-scale nature of fractures that may lead to development of through-going fractures (Petrie et al., a, in prep). We examined the geochemical character of the altered and mineralized rocks, and related these physical descriptions to the geochemical nature of the rocks. Phase 4 included data synthesis and building of 3-D models of rock fracture that depict the distribution of fractures, faults, and alteration patterns. [Petrie et al., b, in prep.]

We focused on field and laboratory analyses of the natural geologic controls on the development of flaws in otherwise high matrix seal capacity (high entry-pressure) caprocks/ mudstones that may ultimately lead to leakage of single- or two-phase fluids at 1-3 km depth conditions. We quantified the nature and conditions of the fracture and fault-related flow in the caprocks, and determined the nature of carbonate mineralization in the rocks. This included addressing the following questions:

- How are seal by-pass systems influenced by depositional factors, mineralogy, pore structure, texture, structural/tectonic history, and diagenetic and burial history? (Task 2)

- What are the geologic controls on the various types of microscopic and mesoscopic fracture patterns/networks in mudstones from field and drill core samples from as deep as $1400 \mathrm{~m}$ ? The sedimentological nature of the caprocks, and their relationships to deformation contribute to these controls. (Task 2 and 3 )

- What are the mesoscopic fracture patterns that form in mudstones from $\mathrm{CO}_{2}$-rich and $\mathrm{CO}_{2-}$ barren settings? At what scale do fractures become important for degrading sealing capacity? What are the scaling relationships of fractures for seal lithologies at depths suited for $\mathrm{CO}_{2}$ sequestration? (Task 3)

- Can we develop conceptual and statistical-based 3-D models for understanding the linkages/connections/correlations between rock properties that control capillary-entry pressure and other matrix-scale-sealing behaviors and the rock properties that control the attributes of seal bypass features? (Task 4 )

\section{Methods}

\section{1a. - Field Work}

The objectives of fieldwork were to examine exhumed natural $\mathrm{CO}_{2}$ flow systems in which $\mathrm{CO}_{2}$ flowed in porous and permeable units, where $\mathrm{CO}_{2}$-related flow occurred across overlying lowpermeability mudstones, and to examine the mineralization that occurred in caprocks. This work consisted of field-based characterization of micro- to meso-scale fractures in outcrops of argillaceous caprocks, supplemented with (microscopic) laboratory analysis of fracture characteristics, mineralogy, rock fabric, sedimentological character, diagenetic patterns, and fluid inclusion compositions.

We examined field sites where we had done preliminary fieldwork and knew that fracture systems (mineralized and non-mineralized) are well exposed, with a focus on fracture density, fracture lengths, distribution of alteration and mineralization, morphology, mineral infilling, and their relationships to lithology. We used 1-D scan lines, 2-D scan area techniques, and ground-based photo-imaging investigations to quantify the distribution of the fractures, and scan lines across faults to evaluate their character and relationships to alteration.

All data were collected in a georegistered field database, and coupled with 1:4000 scale mapping with detailed topographic bases, air photo images, and GoogleMap ${ }^{\mathrm{TM}}$ images document the patterns of 
fractures, faults, and alteration at the sequestration site scale. We focused on units that are candidate seal units for $\mathrm{CO}_{2}$ demonstration projects (http://www.southwestcarbonpartnership.org/) or likely storage units for coal-fired power plants of the Colorado Plateau region (Allis et al., 2001). We have also worked in all of these units and have identified areas where they are well exposed, exhibit deformation, display evidence for the flow of reducing fluids or gas, and where there are control sites with little deformation that could be used to determine the undeformed rocks and compare the nature of deformed and undeformed rocks.

This fieldwork occurred at three sites [Figure 1], all of which we have worked on in the past or have done preliminary work on. Most of this work focused on the San Rafael Swell. The San Rafael Swell is an asymmetric, east-vergent, doubly plunging anticline with a NNE-trending axis (Davis and Bump, 2009; Bump and Davis, 2003). Estimates on timing of formation of the San Rafael Swell range from $83.5 \mathrm{Ma}$ to $58 \mathrm{Ma}$ (Fouch et al., 1983; Lawton, 1986; Guiseppe and Heller, 1998; Shipton and Cowie, 2001).

- $\quad$ Little Grand Wash / Salt Wash Area: The Little Grand Wash and Salt Wash areas are marked by the presence of normal faults along which $\mathrm{CO}_{2}$ has migrated upward from $>1 \mathrm{~km}$ depth (Shipton et al., 2005; Williams, 2007; Heath et al., 2009). Flow in and around these faults has occurred for over 100,000 years (Burnside et al., 2007) and is marked by ubiquitous calcite veins and bleached zones around small faults and fractures. Our targets are the Jurassic Summerville and Tidwell and Brushy Basin members of the Morrison Formation. We focused on moderately deformed portions of these rocks, where 5-10 m offset

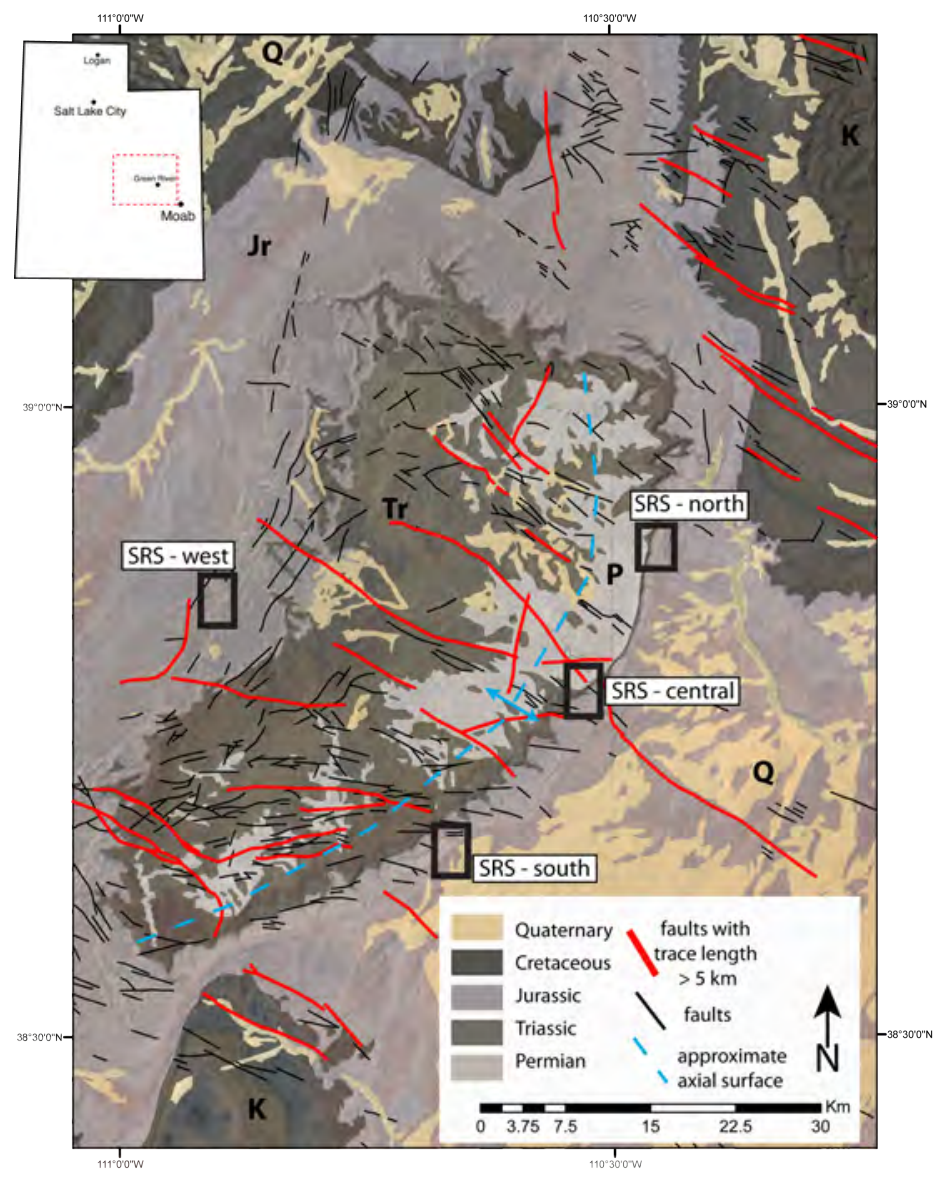

Figure 1. Simplified geologic map of the San Rafael Swell (SRS) draped over air photo. Fault trace lengths $>5 \mathrm{~km}$ highlighted in red; field areas shown by black rectangles. 
faults and numerous open-mode joints and joint swarms cut the lower sandstones and the overlying shale, and the fractures in the shale are all bleached.

- Hite / Glen Canyon area: This area is the deepest in the section, where nearly flat-lying Permian White Rim Sandstone is overlain by the Moenkopi Formation. Small-displacement $(<5 \mathrm{~m}$ throw) faults and fracture are exposed in map and vertical sections in the Hite region, where the fall of Lake Powell has provided newly accessible exposures of these rocks. The faults die out up section into the shale and siltstone portions of the Moenkopi Formation, and we can see the manifestations of deformation in the shaley sequences. The faults and fracture zones are bleached and stand out in sharp contrast with the red host rocks.

- Central San Rafael Swell: The Middle to lower Upper Jurassic Carmel Formation is the proposed primary seal to the underlying Navajo and Page Sandstone sequestration targets and can be used as an analog for other heterolithic mixed carbonate siliciclastic seals (Allis et al., 2003; Esser et al., 2010; NETL 2010). At the study locality the Carmel Formation dips gently $\left(9 \pm 2^{\circ} \mathrm{W}\right)$ and unconformably overlies the Navajo Sandstone. The Carmel Formation is a mixed siliciclastic carbonate unit deposited in shallow marine to sabkah environments (Hintze, 1988; Blakey, 1994; Caputo, 2003). The underlying Navajo Sandstone is a thick-bedded, well-sorted, very-fine to medium-grained permeable quartz sandstone deposited in a large erg (Hintze, 1988; Hansen, 2007). All four members of the Carmel Formation are exposed at this locality. These include: 1] the basal thin-bedded shale and sandy limestone of the Co-op Creek Member; 2] overlain by the medium to thick-bedded gypsiferous sandstone, mudstone and anhydrite layers of the Crystal Creek Member; 3] the siltstone and mudstones of the Paria River Member; and 4] the lower portion of the Windsor Member, interbedded micritic limestone and calcareous mudstone and siltstone (Hintze, 1988; Caputo, 2003; Sprinkel, 2010, personal communication). The Co-op Creek and lower Crystal Creek Members make up the basal $9 \mathrm{~m}(29.5 \mathrm{ft}$ ) of the Carmel Formation and are considered in this study to be the primary seal to the underlying Navajo Sandstone. This portion of the Carmel Formation is dominated by thin- to medium-bedded bioclastic micritic limestone, which contains very fine to fine-grained quartz clasts and interbedded clay with rich, fissile to tabular siltstone and mudstone. 
- Macroscopic-scale analysis of each monocline included processing of satellite imagery, analysis of depth and thickness of units from available wellbore data, and creation of depth contour maps. At the mesoscopic scale, fracture spacing acquired from scan line station measurements identified increased fracture frequency in proximity to major fault zones. At the microscopic scale, percentage of degradation and type of mineralization in pore space were used to verify increased fluid flow in proximity to major fault zones. Faults with possible intersections with multiple antithetic faults at depth have an increased probability of allowing for upward migration of fluids and/or hydrocarbons along the fault plane and damage zone, effectively bypassing the top sealing formations. Mesoscopic scan line data show that discrete faults in the sandstone reservoirs tip out into the overlying "seal," and that the tip zones are typically characterized by 10--120 m wide zones of bleached and altered fracture zones, often with carbonate vein filling. Fractures cut fine-grained cap rocks, and extend up section 10's or in some cases, 100's meters from the reservoir rock.

Fault leakage potential maps identified areas where seal bypass along major faults would likely occur during sequestration of $\mathrm{CO}_{2}$. The method was validated by identifying potential migration pathways for oil seeps on the Little Grand Wash fault in central Utah. The San Rafael Swell was geometrically modeled through restoration of eroded formation tops along the fold axis to quantify the interaction between an outward migrating $\mathrm{CO}_{2}$ plume and varying degrees of faulting and fracturing. Analysis of a hypothetical migration of a $\mathrm{CO}_{2}$ plume front through time exhibited an increasing probability of the outward migrating plume intersecting a leakoff fault or fracture zone, with the highest probability of the advancing plume intersecting a potentially leaking feature achieved when faults with $1+\mathrm{km}$ trace length and mean fracture spacing of $17 \mathrm{~cm}$ are taken into consideration.

\section{1b. Core-Based Analyses}

This work supplemented field-based analyses, enabled microstructural and mineralogical characterization of less-disturbed samples, and allowed us to examine fracture-mineral-host rock relationships from depth in a presently $\mathrm{CO}_{2}$-charged system. Numerous natural accumulations of $\mathrm{CO}_{2}-$ dominant gases occur throughout the greater Colorado Plateau and Southern Rocky Mountain region (Allis et al., 2001). At Green River, $\mathrm{CO}_{2}$-laden fluid leaks to the surface along the crest of the Green River anticline through a number of abandoned petroleum exploration wells and the through the damage zone of the footwall block of the Little Grand Wash and Salt Wash normal fault systems (Dockrill and Shipton, 2010; Shipton et al., 2005; Shipton et al., 2004). The 160-330m depth of the upper $\mathrm{CO}_{2}$-bearing reservoir, the Navajo Sandstone, around Green River and the prior knowledge of the site made it an excellent drilling target (Assayag et al., 2009; Baer and Rigby, 1978; Burnside et al., 2013; Dockrill and Shipton, 2010; Evans et al., 2004; Gouveia and Friedmann, 2006; Gouveia et al., 2005; Gratier et al., 2012; Han et al., 2013; Heath, 2004; Kampman et al., 2009; Kampman et al., 2012; Shipton et al., 2004; Wigley et al., 2013a; Wigley et al., 2013b; Wigley et al., 2012; Wilkinson et al., 2009).

Drilling of CO2W55 into this system, with private funding, was carried out in July 2012 using a CS4002 Truck Mounted Core Drill. The drill site was on the footwall block of Little Grand Wash Fault (38.93792 N, $110.13892 \mathrm{~W}, 1238 \mathrm{~m}$ Elev.), 250 m to the west of Crystal Geyser - an abandoned petroleum exploration well, that now hosts a $\mathrm{CO}_{2}$-driven cold water geyser (Assayag et al., 2009; Baer and Rigby, 1978). The vertical hole was drilled to a depth of $322.5 \mathrm{~m}$ using DOSECC's hybrid coring system, with core recovery close to $100 \%$. On site processing of the core involved core description, photographing and selective anaerobic bagging of important core sections in nitrogen-flushed vacuum-packed aluminised bags. Downhole logging of the hole was not conducted due to the depth of cementation.

Core analysis included lithologic and structural logging of the core, and sampling where appropriate for the zones that exhibit fractures and faults. The undeformed core provided a baseline of rock textures that document the original sedimentologic character of the rocks, and the deformed core allowed us to examine and compare the nature of deformation at the surface sites and the subsurface conditions. 


\section{1c. Laboratory Analyses}

Outcrop and core-based scales of study revealed the nature of fractures in relationship to underlying stratigraphy and the relationships to sedimentologic variability, thereby establishing the nature of mineralization, and provided samples for microscopic and geochemical analyses. These analyses consisted of:

i. Microscopic (optical and electron) analyses of primary sedimentologic textures and microfractures. This work established the nature of the microfractures that are likely the first stage of fracture growth, and quantified the relationship between sedimentologic and diagenetic variations and the nucleation and development of fractures. We also evaluated the nature and distribution of cements with optical and scanning electron methods in the rocks to begin to discern the nature of the diagenesis these rocks have experienced. Scanning electron microscopy with elemental analyses established the very fine-scale relationships between $\mathrm{CO}_{2}$-fluid flow and the pores and grains within the rocks.

ii. Mineralogical analyses, primarily x-ray diffraction studies of host-rock composition, in order to determine the nature and extent of fluid-rock interactions in the systems. We used qualitative and semiquantitative methods for evaluation. In addition, mineralogical studies documented the nature and degree of $\mathrm{CO}_{2}$-bearing fluid-rock interactions to establish how seal rocks may seal due to pore space invasion versus microfracture development.

iii. Compositional and stable isotope analyses to support the textural studies in terms of establishing the grain scale to microfracture to mesoscopic-fracture mineral interactions. We used elemental analyses with standard whole-rock geochemical analyses, supported by EDAX analysis, and stable isotope signatures ( $\delta{ }^{13} \mathrm{C}$ and $\delta{ }^{18} \mathrm{O}$ ) to evaluate the evolution of fluids and to help define flowpaths in the rocks.

\section{1d. Modelling}

The final effort involved mechanical modelling of the fractured rock masses, and examining how bulk permeability and porosity is affected by the distribution and orientation of fractures and faults. The fieldwork established the thickness, extent, and nature of the sedimentary rock units, and location of major faults. Creating rock fracture models required evaluation of the data for appropriate methods of statistical analyses, and established which parameters will be varied in doing a sensitivity analysis of how variations in rock fracture affect the bulk porosity and permeability of the rock mass. Software tools FRACMAN $^{\mathrm{TM}}$ and FRED ${ }^{\mathrm{TM}}$ allowed us to create multiple realizations of fracture and fault distributions from starting data populations, and to evaluate how different statistical models (e.g. random; clustered; fault damage zone; variation in orientation, thickness, etc.) affect the bulk flow properties. Simple finite element modeling using ABAQUS software examined modelling of the effects of different stress states [including pore pressure] on the fractures by varying their aperture, using closing as a proxy for higher fracture normal stresses.

\section{1e. Technological Developments}

Additional aspects of this work include new methods to examine rocks in the field in order to quantify the nature of fractured rock at a series of scales. Most of this effort involved the adaptation of technology or methods developed elsewhere to the questions we posed here. In some cases, these adaptations are among the first use of the methods in the analyses of fractured rocks. These adaptations considerably shortened the time needed to complete our investigations. These advancements include:

i. Use of ASTER data to determine location of mineralization. Barton (2011) screened the region for target sites to be used for future fieldwork with the use of ASTER data, processed with Adobe Photoshop software. Advanced Spaceborne Thermal Emission and Reflection Radiometer (ASTER) sensor aboard the NASA Terra platform returns reflectance values that can be processed in a variety of ways to enhance the ground surfaces signature. Barton (2011) used the methods $\begin{array}{lll}\text { developed by } & \text { bSIRO }\end{array}$ (http://c3dmm.csiro.au/Australia_ASTER/Australian\%20ASTER\%20Geoscience\%20Product\%20Note s\%20FINALx.pdf) to search for $\mathrm{Ca}, \mathrm{Na}$, and $\mathrm{K}$ mineralization. He identified regions as small as $30 \mathrm{~m}$ on a side that returned signatures that indicated the presence of fluid-assisted alteration, and then field checked these sites. In all cases, the ASTER data accurately predicted the location of altered 
rocks that warranted further work.

ii. Examination of fractured rocks with Sirovision to quantify rock stratigraphy and fracture character. Petrie et al. (2012), Richey et al. (in press) used a simple photogrammetric technique developed by CSIRO to characterize outcrop-scale features. Adapting the work of Haneberg (2008), we use this ground-based stereo-photogrammetric method to accurately, affordably, and rapidly quantify the location and dimension of rock bodies and fractures. This method is especially useful in capturing the nature of outcrops 1-100 m long or high, and in sites where access is difficult, such as cliffs, vertical road cuts, and arroyos. Using the software Siro3D, we can measure the orientations, dimensions, and locations of key features in the rock. This technique helped determine the nature of the rock packages described in Petrie et al (2012).

iii. Determination of relative permeability with TinyPermll. We use New England Research's TinyPermll, a handheld air permeameter, to evaluate the relative permeability of deformed rocks at the outcrop. This pneumatic tool injects air into a $5 \mathrm{~mm} \mathrm{~cm}$ diameter spot on the rock face. While limited at the lower bound by permeability, this method was used to examine at the field scale the nature of rock properties (Petrie et al., 2012).

iv. Determination of relative elastic properties with a Schmidt hammer. The Schmidt hammer is a spring-loaded tool that measures the elastic rebound at a face. It was originally designed to evaluate the properties of concrete, and has been adapted by Selby (1980 among others, for use in geology. We use the tool here to evaluate elastic properties, and in conjunction with fieldwork, TinyPerm II measurements, and wireline log analyses, we show how to integrate the elastic properties in evaluating the strength of the rocks.

v. Quantification of paleoflow pathways with ultraviolet lighting. Petrie et al. (in press) used an ultraviolet light source at night to illuminate the location of $U$ and Ca-rich mineralized zones in rock. In many places this mineralization occurred in previously thought low-permeability fault zones, and Petrie et al. (in press) show how at some sites the paleo-flow history in the rocks is more complex than previously thought.

vi. Laboratory analyses of $\mathrm{CO}_{2}$-water-rock interactions. Nathan Gilies, an undergraduate using largely university funds and a modest amount of funding from this grant designed, built, and ran twelve $\mathrm{CO}_{2}$ gas-rock-water flow experiments. The apparatus uses mostly off-the-shelf components, and consists of $\mathrm{CO}_{2}$ gas flow through sealed sampled saturated in waters that range from distilled water to brine chemistry that mimic in situ waters. These experiments are run at room temperature and pressure, and do not mimic subsurface conditions - these experiments show how $\mathrm{CO}_{2}$ gas might interact above supercritical conditions (Gilies and Evans, 2011). These experiments examined the DeGeerdalen Formation from Svalbard, Norway, the Navajo Sandstone, Entrada Sandstone, Nugget Sandstone, and Mancos Shale from the San Rafael Swell, Utah. We also examined a fossiliferous Indiana Limestone to observe the reaction within carbonates. Further improvements to the system lie in the area of plating all of the components to eliminate pitting due to the corrosive nature of high-pressure $\mathrm{CO}_{2}$.

vii.

\section{Results and Discussion}

\section{2a. Regional and Map-Scale Character of Reservoir-Seal Fracture Systems}

The regional analysis of the structure of the San Rafael Swell identified numerous sites for further detailed study (Barton, 2011; Petrie et al., in press). This work also examines the evidence for, and implications of, regional- and reservoir-scale naturally occurring $\mathrm{CO}_{2}$ leakage in the San Rafael Swell. Natural exposures of reservoir and top seal pairs in central and southeastern Utah were identified as analogs to proposed $\mathrm{CO}_{2}$ injection targets. Our work examined regions at the macroscopic (map and larger), mesoscopic (outcrop) and microscopic scales. 


\section{Macroscopic Scale Characterization}

Barton (2011) identified areas that exhibited the possible presence of kaolinite and color alteration of host rock on the eastern limb of the San Rafael Swell on the basis of analysis of ASTER data [Figure 2] and the selected sites were field checked for accuracy of the spectral analysis methods. Individual target field areas within the San Rafael Swell were chosen based on the combination of host rock alteration in blue and kaolinite alteration in orange [Figure 2]. Alteration features identified in outcrop include mineralized veins in fractures, color alteration of host rock, color alteration along fractures, and mineralization associated with faults and fractures.

Barton (2011) examined an area $250 \times 200 \mathrm{~km}$ in the San Rafael Swell focus areas [Figure 2], and a minimum structural feature size of $\sim 5 \mathrm{~km}$. At this large scale we used fault scaling relationships (Cowie and Scholz, 1992; Clarke and Cox, 1996) to identify faults that we assume will have at least 10-20 $\mathrm{m}$ of displacement to be those with a trace length $>5 \mathrm{~km}$ [Figure 3]. Using the Utah state geologic map (Hintze et al., 2000) as well as the geologic map of the Huntington 30'x60 quadrangle (Witkind, 1988) and the interim geologic map of the San Rafael Desert 30'x60' quadrangle (Doelling, 2002), we identified fault traces that exceed $5 \mathrm{~km}$ in length [Figure 3]. Previous research suggests that the width of damage zones increase with accumulation of offset (Shipton and Cowie, 2001), and these damage zones will affect permeability and fluid flow locally (Caine et al., 1996). We assumed that faults with possible intersections and multiple antithetic faults at depth have an increased probability of allowing upward migration of fluids along the fault plane and damage zone, effectively bypassing the top sealing formations. As a first step, map-based ( $\mathrm{km}$ scale) evaluation of fault trace length was used to identify faults for the creation of fault leakage potential ${ }_{110^{\circ} 15^{\prime} 0^{\prime \prime} \mathrm{W}}$ maps [Figure 3B].

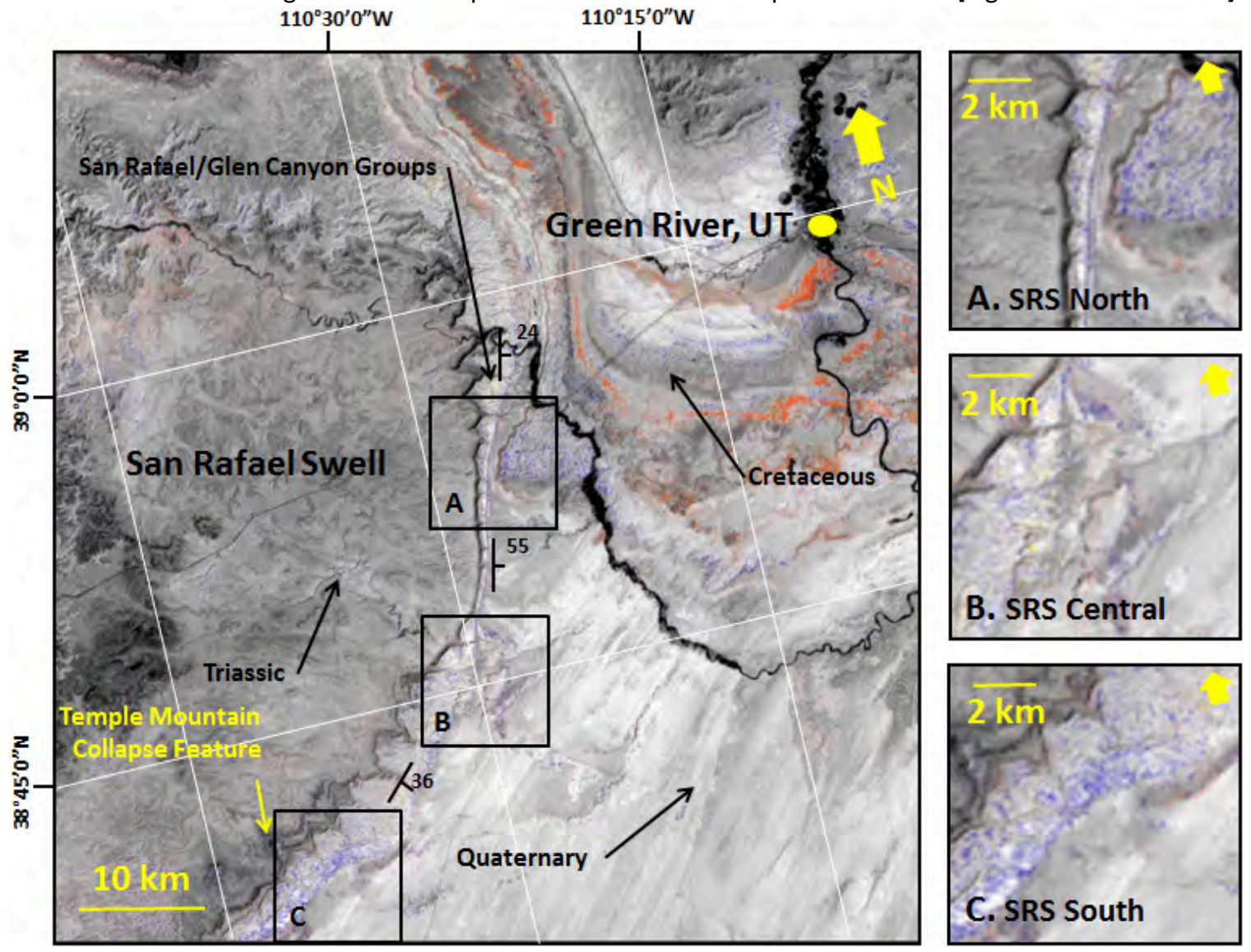

Figure 2. Processed ASTER $30 \mathrm{~m}$ satellite image (4000x4000 pixel) with kaolinite (orange) and host rock alteration (blue) overlays. (A) SRS North field area (North) (B) SRS Central field area (Central) (C) SRS South field area (South). 
The San Rafael Swell was geometrically modeled using IHS Petra ${ }^{\mathrm{TM}}$ through restoration of eroded formation tops and modeling of fault traces at depth to quantify the interaction between an outward migrating $\mathrm{CO}_{2}$ plume and varying degrees of faulting and fracturing; the likelihood of leakage increasing as fault-fault interactions increase [Figure 3]. Geometric restoration of the fault interactions at depth and structural contours were done in IHS Petra ${ }^{\mathrm{TM}}$ using isopach maps and fault trace data. Isopach maps were created using 497 publicly available well tops information from the Utah Division of Oil, Gas, and Mining (for a complete list of data see Barton, 2011), fault trace data was derived from regional maps (Witkind, 1988; Hintze et al., 2000; Doelling, 2002). Antithetic dipping fault and deformation bands are observed in orthorhombic fault arrays in the San Rafael Swell (Krantz, 1988; Shipton et al., 2002; Davatzes et al., 2003; Johansen and Fossen, 2008).

An increased potential for fluid migration along fault planes is anticipated if projected surface traces of mapped antithetic faults intersect with individual fault planes at depth. Fault planes are color coded to represent the number of antithetic faults a single fault interacted with at depth [Figure 3]. At the map scale, analysis of the potential subsurface interaction of faults within the San Rafael Swell shows increased probability of at-depth interactions between major faults (> $5 \mathrm{~km}$ trace length). It is assumed that at each fault intersection, the potential for migration laterally along the fault plane or upward through seals is higher than along faults with no fault-fault interactions. This map does not predict where leakage points occur, but it can be used as a tool to evaluate the risk of leakage [Figure 3]. 

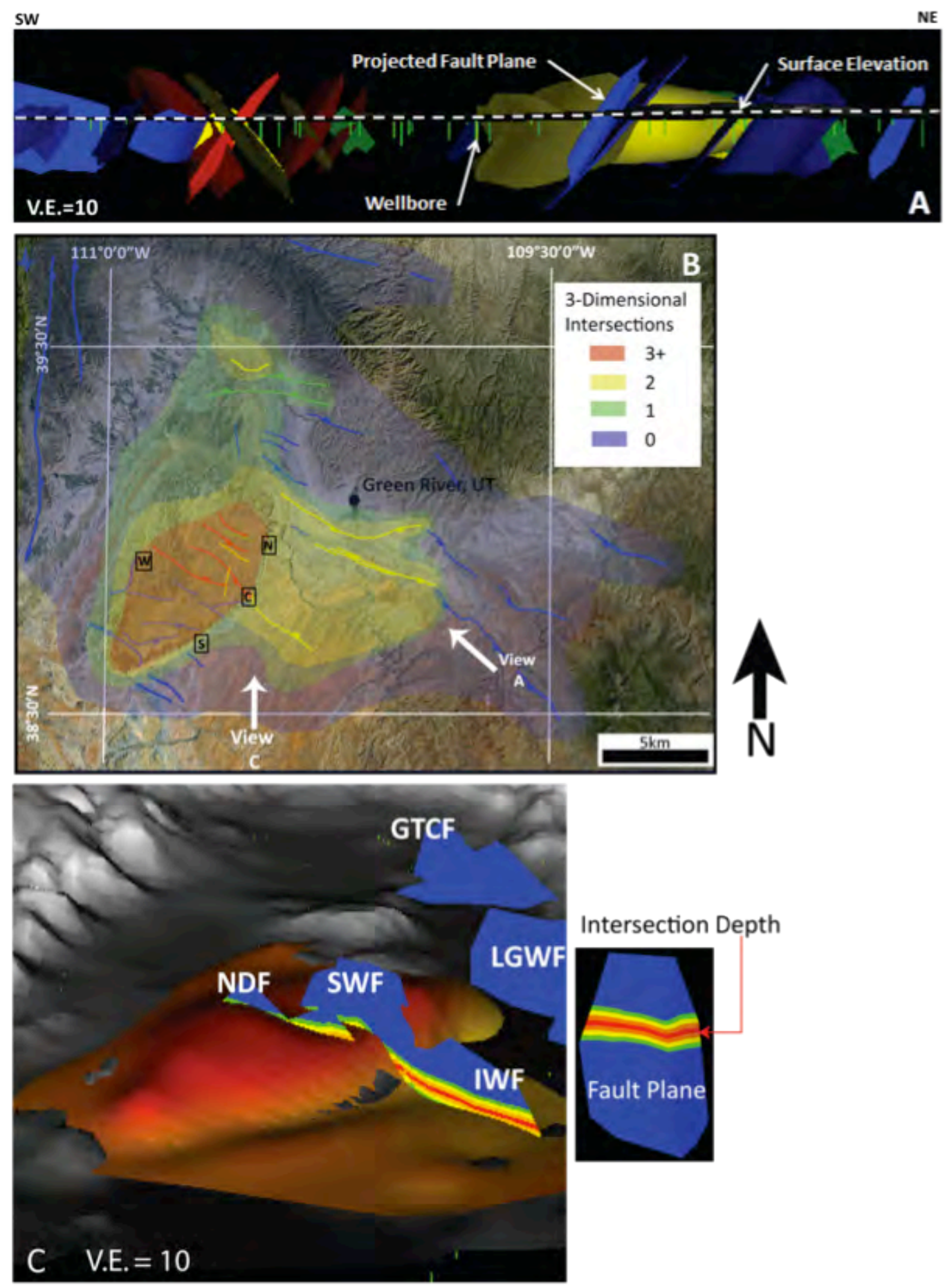

Figure 3. A) Modeled fault plane projections of major faults $(5+\mathrm{km}), \mathrm{V} . \mathrm{E} .=10$. Planes are color coded by number of three-dimensional fault-fault interactions at depth. B) Map view of fault leakage potential. Boundaries are approximated by three-dimensional fault-fault interactions and the structural reconstruction contours of the San Rafael Swell. Black boxes highlight field areas, N = SRS North, C = SRS Central, $\mathrm{S}=$ SRS South, $\mathrm{W}=$ SRS West. C) Oblique view of modeled fault plane projections of major faults $(>5 \mathrm{~km})$ with surface reconstruction of the Navajo Sandstone. NDF = Nielson Draw Fault, SWF = Straight Wash Fault, IWF = Iron Wash Fault, LGWF = Little Grand Wash Fault Zone, GTCF = Grassy Trail Creek Fault (Barton, 2011; Petrie et al., 2013). 
Outcrop observations for key sites and scan-line data are summarized in Table 1 and in Figures 4 and 5. Fracture-associated mineralization and alteration of host rock at each locality includes calcite veins, symmetric calcite and hematite mineralization on open fractures, and alteration halos in host rock adjacent to fractures [Figure 4]. Fracture morphology includes continuous fractures that cut various lithologies across bed contacts, deflection of fractures at lithologic contacts, and termination of fractures within beds and at lithologic contacts between beds. Fracture spacing is higher in the Navajo Sandstone at all localities, with fewer fractures encountered per meter along the scan-line within the Navajo Sandstone. Fault deformation bands are observed at all localities within the Navajo Sandstone. The zones of fault deformation bands transition into open-mode fractures in the overlying Carmel Formation with associated veins and alteration halos, suggesting fault parallel, vertical fluid flow and breaching of the seal well above the reservoir seal interface.

Fracture strike orientation data are consistent with that of the larger regional, map-scale, structures, with dominant WNW strike orientations on the eastern side of the San Rafael Swell and an ENE orientation on the gently dipping western limb. The dominant structural orientation of the San Rafael Swell changes along strike becoming more E-W directed in the southernmost San Rafael Swell, this change is also reflected in fracture orientation data. Fracture orientations at each field site are generally consistent between the reservoir-seal pair, although some variability exists within the individual formations. 

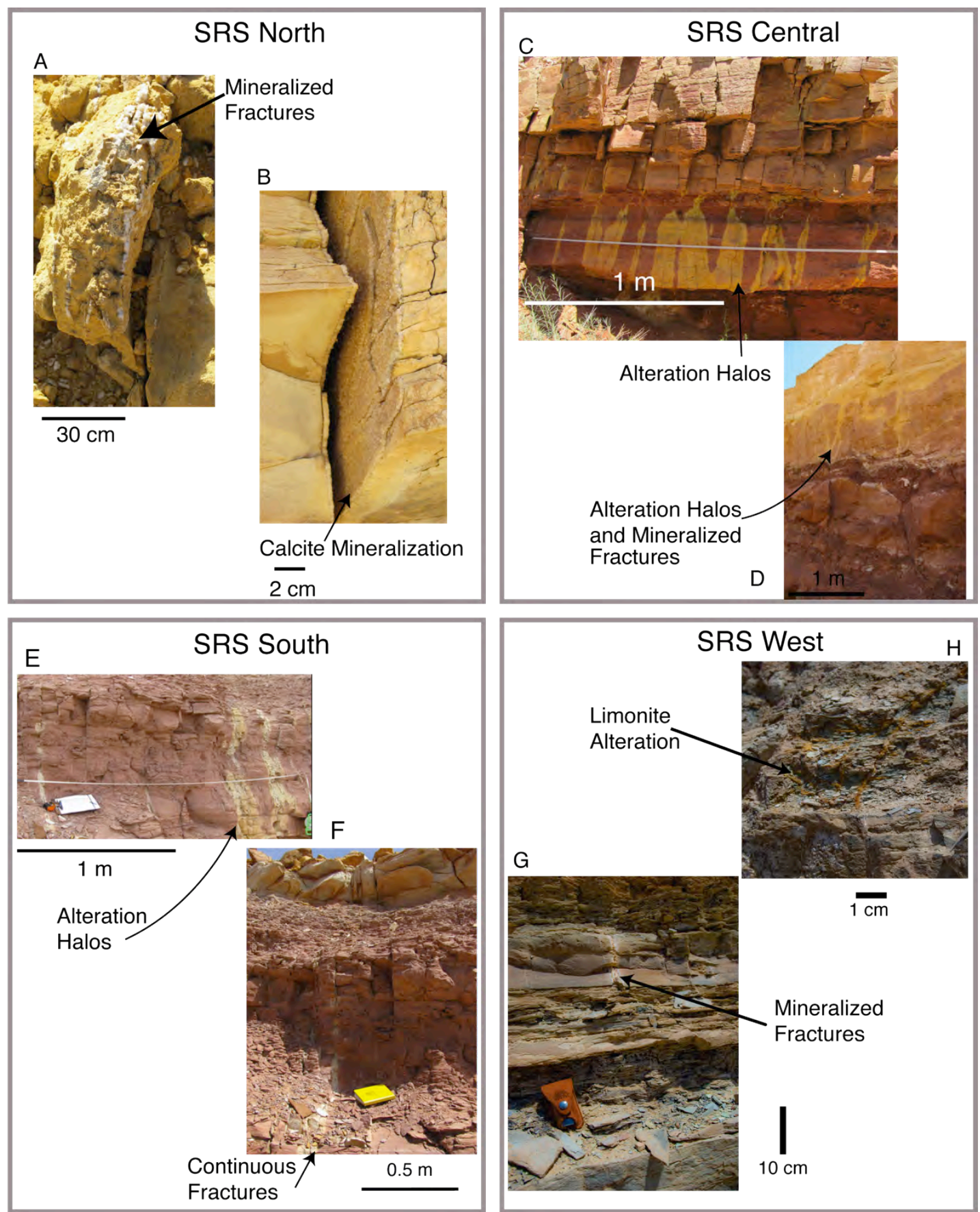

Figure 4. Field examples of fracture morphology, mineralization, and alteration in caprock. North, Central, South, and West refers to field locality, see figures 2\&3. SRS North A - mineralized fractures in the Navajo Sandstone; SRS North B - Symmetric calcite mineralization on each face of an open fracture in the Carmel Formation. SRS Central C - Alteration halos and mineralization of fractures in the Carmel Formation; SRS Central D - Continuous fractures across bedding interface of Carmel Formation and overlying Entrada Sandstone. SRS South E - Alteration halos in Carmel Formation; SRS South F - Alteration halos and continuous fractures across bedding interface of Carmel Formation and overlying Entrada Sandstone. SRS West G - Calcite veins in thinly bedded argillaceous limestone of the Carmel Formation; SRS West H Limonite halos associated with fractures in interbedded shale of the Carmel Formation; the limonite halos highlight the deflection of fractures within the shale. 


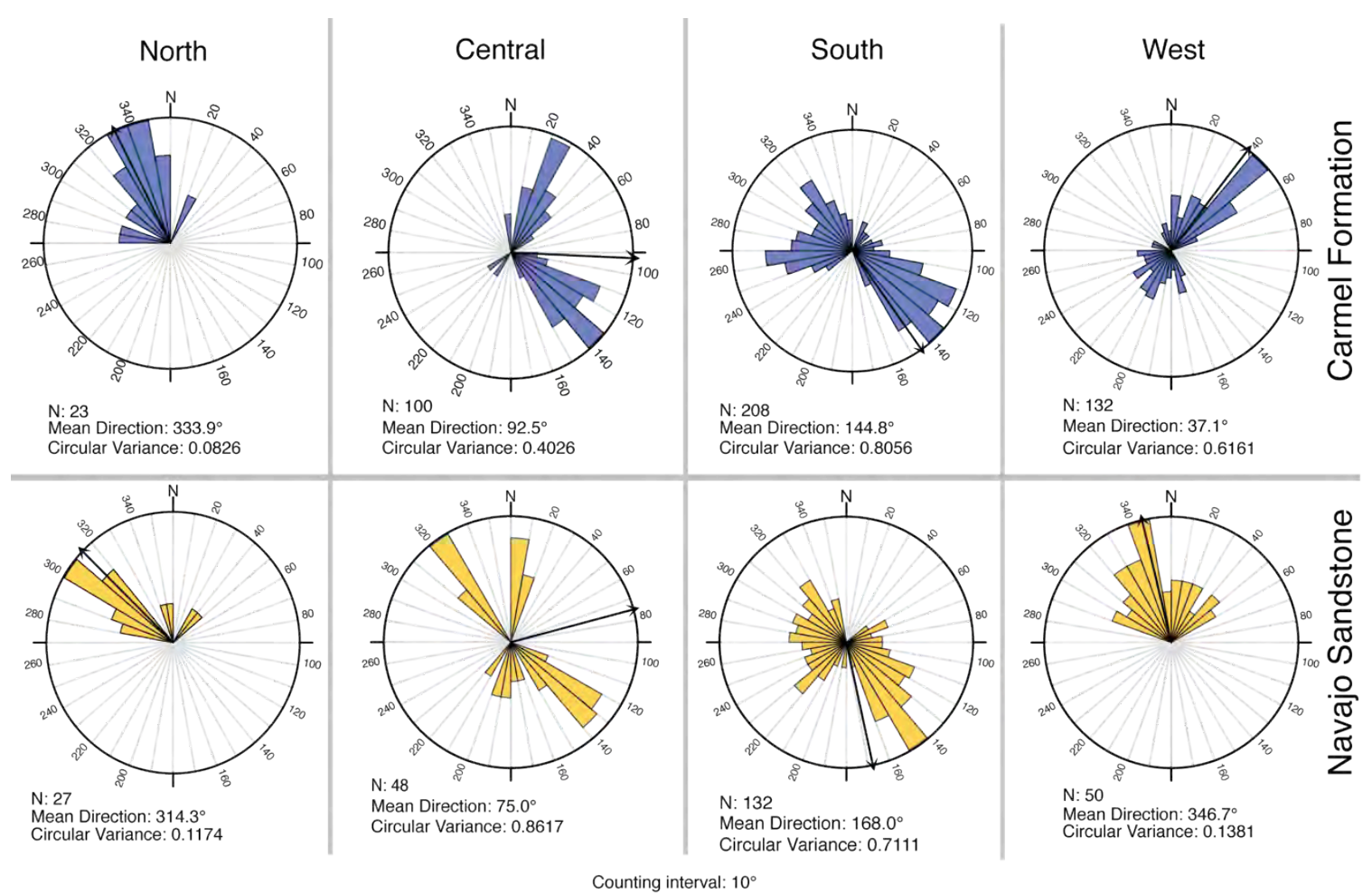

Figure 5. Strike orientation data of fractures in the San Rafael Swell field areas. Blue data are from the Carmel Formation; yellow data are from the Navajo Sandstone.

Richey [2013] examined the Iron Wash fault zone to evaluate evidence for paleo-migration of fluids and/or hydrocarbons along the fault zone. Field mapping, kinematic analysis, petrographic analysis, characterization of the fault zone facies and fault architecture was done along the $25 \mathrm{~km}$ long fault with up to $150 \mathrm{~m}$ of throw to examine evidence for paleo-migration of fluids along the fault and fracture. Field data and observations were combined with well log and borehole data to produce three types of models for the Iron Wash fault: 1) recreation of the geometry of the fault in the subsurface, 2) predictive models of fault zone behavior and fault seal analysis, and 3) predictive geomechanical models of the response of the fault zone in an imposed stress field and while increasing the effective stress on the fault. Model results indicate that the Iron Wash fault zone will likely not behave as a seal for fluids against the fault zone due primarily to modest throw on the fault and nature of the rocks in the hanging wall and footwall, specifically the thick packages of Triassic to Jurassic sandstone [Figure 6]. We conclude that the fault is not likely to develop a sealing membrane and therefore will most likely fail as a seal to fluids moving through the reservoirs modeled here [Figure 6]. Analysis of fluid alteration and mineralization around the fault zone indicates that the fault zone has behaved as a conduit for upwards migration of paleo-fluids. Structural components of the fault zone such as fault relay zones are shown to be areas of incomplete development of fault seal as well as zones of higher fracture intensity and are believed to be areas of the fault where seal-bypass will likely occur [Figure 7]. Structural petrographic analysis of fault rocks shows multiple generations of fluid movement along reactivated fractures and geomechanical modeling supports the notion that there is a possibility of reactivating fractures (or inducing hydraulic fractures along existing fracture planes) during the injection of fluids in the subsurface. 


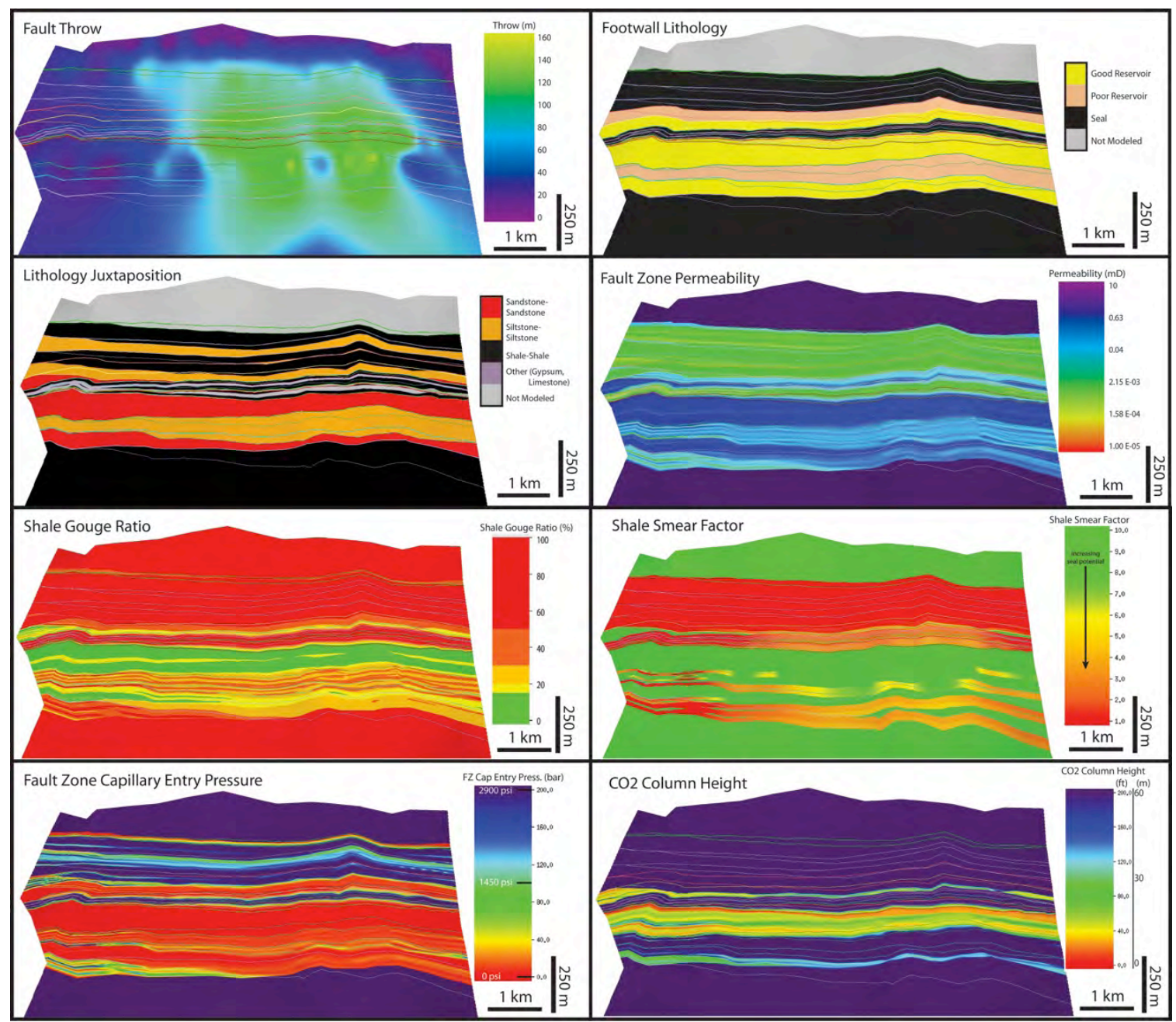

Figure 6. Fault property modeling results showing perspective view of modeled Iron Wash fault plane contoured with various characteristics of the fault zone. Model inputs are the throw on the fault, footwall lithology and lithologic juxtaposition and are used in calculating properties of the fault zone.

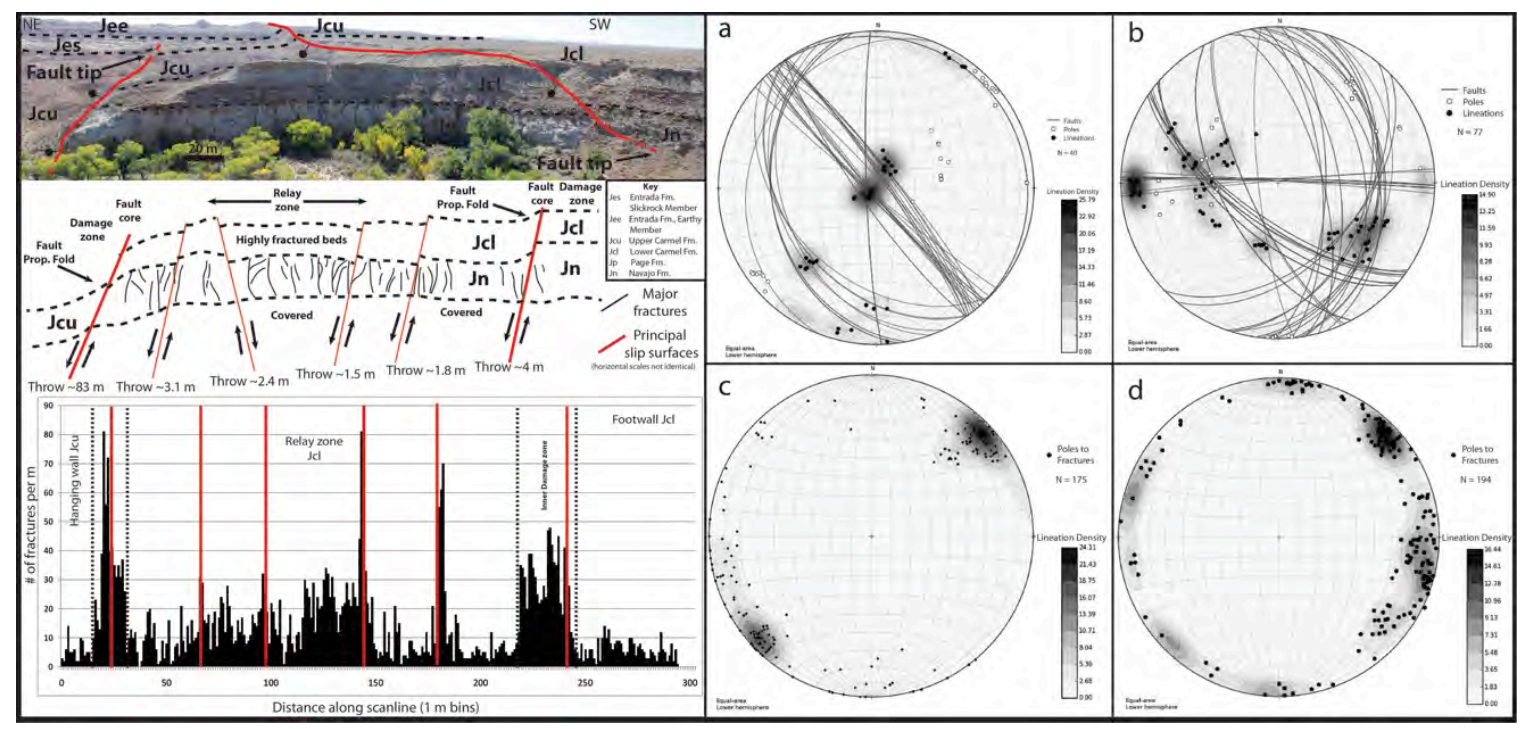


Figure 7. Overview of soft-linked fault relay zone in the Iron Wash fault zone with schematic representation of faults within the fault relay zone and fracture density scanline. Stereograms show orientations of main faults (a), faults within the relay zone (b), poles to fractures outside of the relay zone (c), and poles to fractures within the relay zone (d).

\section{2b. Mesoscopic Analyses}

Petrie et al. (2012) quantified the mechanical properties of caprocks, to determine their variations within the seal across a reservoir-scale analog. Petrie developed a method for predicting of rock strength variability across stratigraphic interface boundaries for cap-rocks in outcrop and subsurface. We evaluated the meso-scale variability in fracture density and elastic moduli in the Jurassic Carmel Formation, a proposed seal to the underlying Navajo Sandstone for $\mathrm{CO}_{2}$ geosequestration, and its potential importance in governing fluid flow. The Middle Jurassic Carmel Formation is well exposed in the San Rafael Swell of east-central Utah and is a mixed, siliciclastic carbonate sedimentary package that contains through-going veins and open joints. We combined mechano-stratigraphic outcrop observations from the Carmel Formation with elastic moduli calculated from publically available wire line log data from to evaluate the variability in fracture pattern as well as the variability in rock strength in this heterogeneous top seal.

We defined 5 mechanical units over a vertical stratigraphic distance of $38 \mathrm{~m}(125 \mathrm{ft})$ in the upper Navajo Sandstone and the lower Carmel Formation. Field-derived rock strength and permeability estimates vary stratigraphically. Compressive rock strength, from Schmidt Hammer rebound values, exhibits higher variability in the thinly bedded heterolithic portion of the lower Carmel Formation, and a decrease in compressive strength in mechano-stratigraphic unit 4 and an increase in compressive strength in unit 5 [Table 2]. The Carmel Formation is a low-permeability unit exhibiting permeability values of less than $7 \times 10^{-15} \mathrm{~m}^{2}$, (0.007 Darcy) throughout the micritic limestone beds of mechano-stratigraphic unit 5 whereas permeability ranges from $16 \times 10^{-14} \mathrm{~m}^{2}$ to $5.2 \times 10^{-14} \mathrm{~m}^{2},(0.002$ to 0.52 Darcy), in units 2 through 4 [Figure 8 and Table 1]. Permeability within the Navajo Sandstone $1 \mathrm{~m}(3.28 \mathrm{ft})$ below the reservoir/seal interface is orders of magnitude higher than the overlying Carmel Formation, permeability measurements within the reservoir have a mean value of $8.7 \times 10^{-12} \mathrm{~m}^{2},(8.8$ Darcy), [Figure 8].

Table 2. Outcrop derived mechano-stratigraphic data for Jurassic Carmel Formation.

\begin{tabular}{|c|c|c|c|c|c|}
\hline \multirow{2}{*}{$\begin{array}{l}\text { Mechano- } \\
\text { stratigraphic } \\
\text { unit }\end{array}$} & \multirow{2}{*}{$\begin{array}{l}\text { Median } \\
\text { bed } \\
\text { thickness } \\
(\mathrm{m} / \mathrm{ft})\end{array}$} & \multirow{2}{*}{$\begin{array}{c}\text { Mean fracture } \\
\text { density } \pm \text { std.dev. } \\
\text { (fracture } / \mathrm{m})\end{array}$} & \multirow{2}{*}{$\begin{array}{l}\text { Median } \\
\text { fracture } \\
\text { spacing }\end{array}$} & $\begin{array}{c}\text { Compressive } \\
\text { Strength } \\
\text { range } \\
\end{array}$ & $\begin{array}{c}\text { Permeability } \\
\left(\mathrm{m}^{2} / \text { Darcy) }\right. \\
\text { range } \\
\end{array}$ \\
\hline & & & & mean & mean \\
\hline \multirow{2}{*}{1} & \multirow{2}{*}{$9.00 / 29.53$} & \multirow{2}{*}{$1.30 \pm 0.99$} & \multirow{2}{*}{0.8} & $21-34$ & $\begin{array}{c}0.4 \times 10^{-13}-1.97 \times 10^{-11} / \\
0.04-19.9\end{array}$ \\
\hline & & & & 28 & $\begin{array}{c}8.4 \times 10^{-12} / \\
8.5\end{array}$ \\
\hline \multirow{2}{*}{2} & \multirow{2}{*}{$0.20 / 0.66$} & \multirow{2}{*}{$5.49 \pm 2.55$} & \multirow{2}{*}{0.5} & $21-50$ & $\begin{array}{c}1 \times 10^{-14}-5 \times 10^{-14} / \\
0.01-0.05\end{array}$ \\
\hline & & & & 39 & $\begin{array}{c}4 \times 10^{-14} / \\
0.04\end{array}$ \\
\hline \multirow{2}{*}{3} & \multirow{2}{*}{$0.15 / 0.49$} & \multirow{2}{*}{$6.16 \pm 1.74$} & \multirow{2}{*}{0.7} & $32-54$ & $\begin{array}{c}2 \times 10^{-14}-4.5 \times 10^{-13} / \\
0.12-0.46\end{array}$ \\
\hline & & & & 44 & $\begin{array}{c}1.2 \times 10^{-13} / \\
0.122\end{array}$ \\
\hline 4 & $1.02 / 3.35$ & $1.05 \pm 0.28$ & 1.5 & $14-42$ & $\begin{array}{c}4 \times 10-14-2.7 \times 10-13 / \\
0.04-0.27\end{array}$ \\
\hline
\end{tabular}




\begin{tabular}{||c|c|c|c|c|c|}
\hline & & & & 29 & $\begin{array}{c}1.1 \times 10-13 / \\
0.11\end{array}$ \\
\hline \multirow{2}{*}{5} & & & & $22-68$ & $\begin{array}{c}6 \times 10-15-9 \times 10-14 \\
0.01-0.91\end{array}$ \\
\cline { 4 - 6 } & $0.59 / 1.94$ & $2.45 \pm 1.82$ & 2.2 & 59 & $\begin{array}{c}6 \times 10-14 / \\
0.61\end{array}$ \\
\hline
\end{tabular}

Field data show that stratigraphic heterogeneity influenced the variability in fracture pattern, rock strength and permeability throughout this exposure of the Carmel Formation. High fracture densities, permeability, and compressive rock strength is observed in the thinly bedded heterolithic facies of mechano-stratigraphic units 2 and 3. A decrease in fracture density, compressive rock strength and permeability are observed in mechano-stratigraphic unit 4, whereas low fracture densities, higher compressive rock strength estimates and very low permeability dominates mechano-stratigraphic unit 5 [Figure 8]. Mineralized veins, step-over fractures and bifurcation are common in mechano-stratigraphic units 2 and 3, while open fractures and fracture swarm behavior is more common in mechanostratigraphic unit 5 [Figure 9]. 


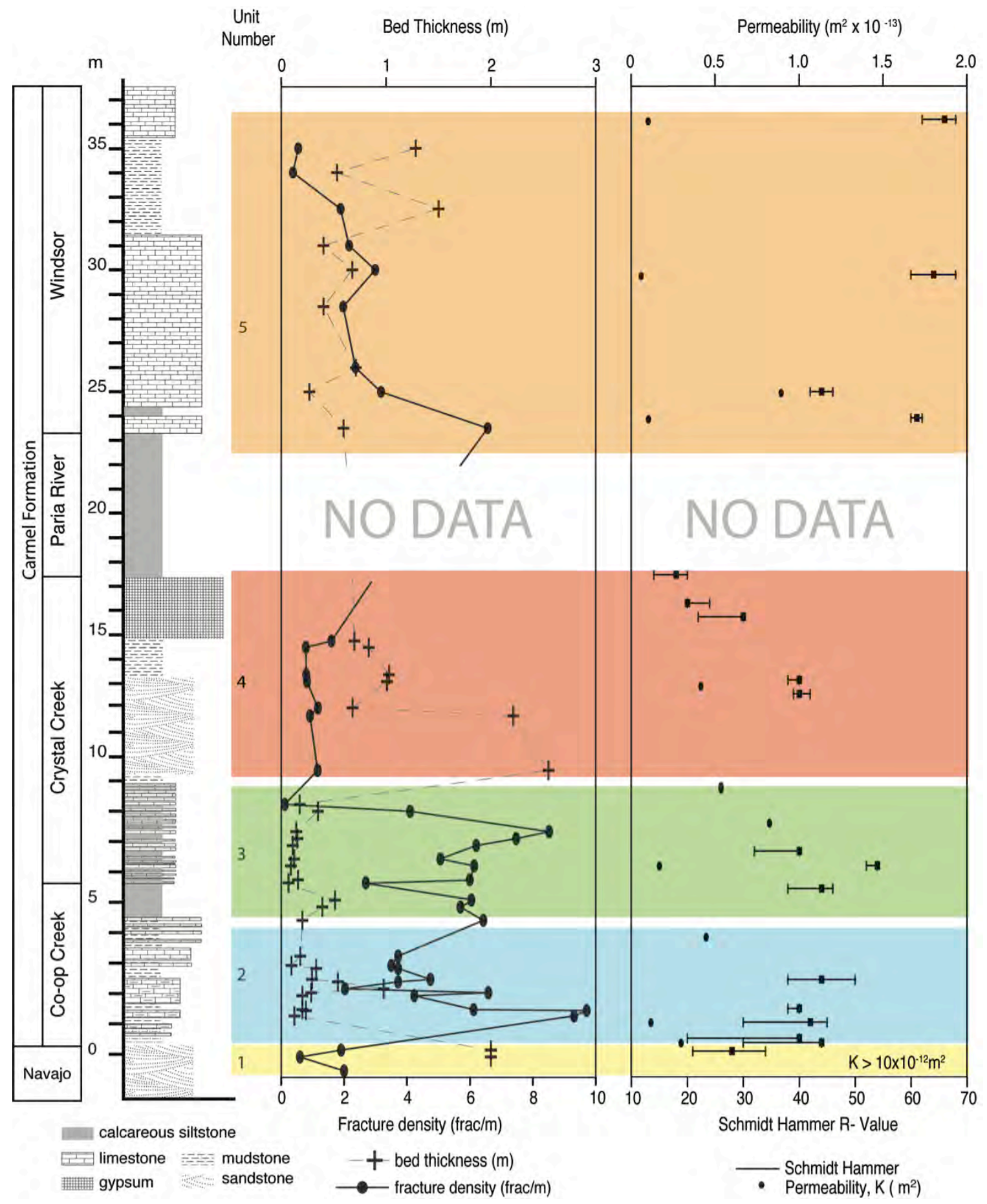

Figure 8. Mechano-stratigraphic data derived from outcrop scanlines and digital orthoimages. Stratigraphic column and associated fracture density, air permeability, and Schmidt Hammer rebound values for rock compressive strength are shown. 


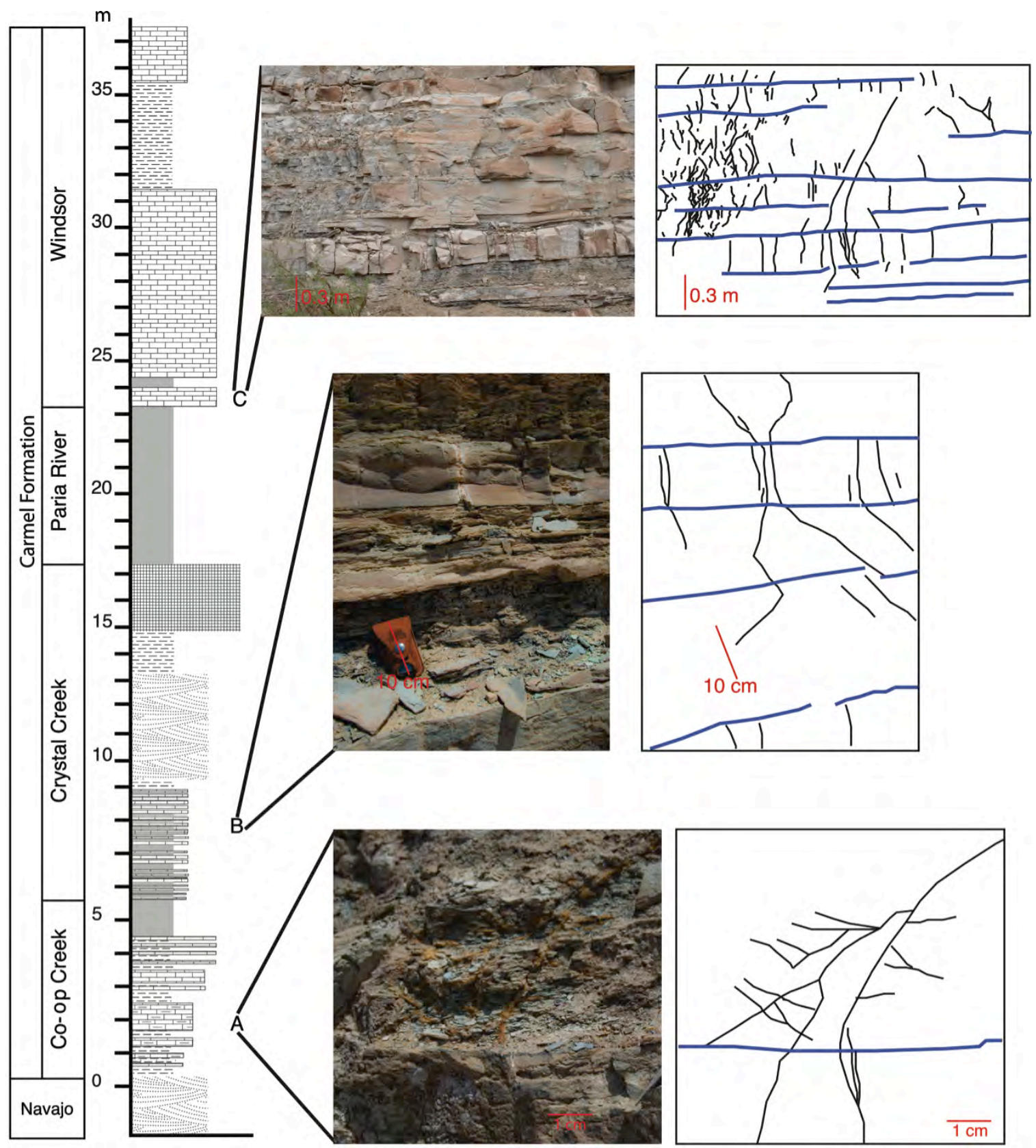

Figure 9.Fracture morphology observed within the Carmel Formation.

The shale horizons of the Carmel Formation exhibit a greater dispersion in fracture orientation data than the limestone and sandstone lithologies [Figure 10]. This data dispersion and its association with lithology indicate that each rock type responds differently to stress, and in a stratigraphic sequence with high lithologic variability highly variable fracture distributions are likely. The distribution of bulls-eye patterns shown in the shale data suggest that its presence and the distribution of this lithology within the sealing facies affect fracture patterns and propagation morphology, which will in turn affect fluid flow at depth. Variability in fracture propagation morphology is also evident within individual beds and across stratigraphic interfaces. This variability may be due to changes in stress localization at lithologic boundaries (Larsen et al., 2010). These morphologies include continuous fractures, fracture termination, fracture step-over, fracture swarm behavior and spaced fractures. The changes in fracture morphology 
across stratigraphic interfaces will affect fluid flow in the subsurface due to changes in connectivity of open fractures across stratigraphic boundaries.

$$
\text { A. }
$$
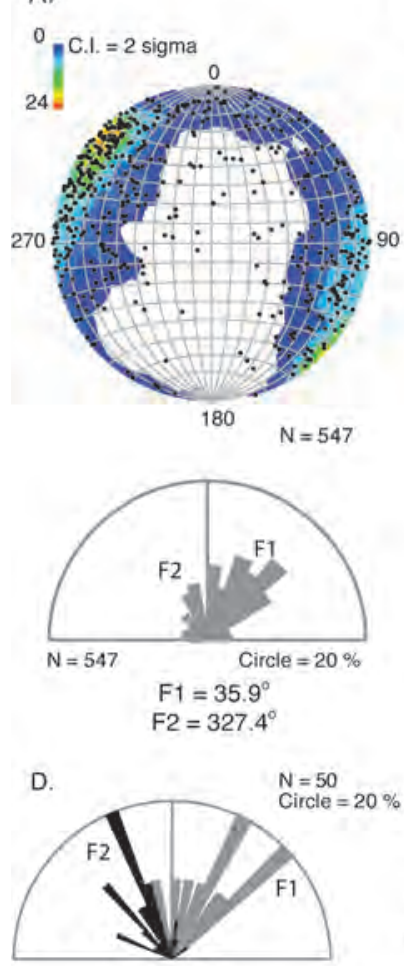

B.
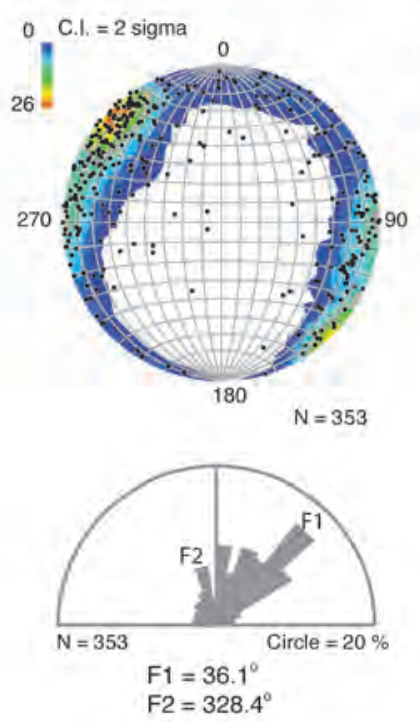

Navajo Sandstone fault deformation band trends, measured on bedding plane $\&$ in cross-section (mean strike orientation $\mathrm{F} 1=21^{\circ}$ )

Joint trend, measured on Navajo Sandstone bedding plane (mean strike orientation $\mathrm{F} 2=337^{\circ}$ )

Figure 10.Orientation data from scanlines in the Carmel Formation and Navajo Sandstone. Stereograms in $A, B$, and C (top), are equal area lower hemisphere projections of poles of fracture planes with Kamb Contours (C.I. 2.0), rose diagrams show the same data. A) All Carmel Formation fracture orientation data, B) fracture orientation data from resistant argillaceous limestone beds, C) Carmel Formation fracture orientation data from shale beds; D) joint and fault deformation band trends measured in the Navajo Sandstone; scanlines done on bedding plane and cross-sectional exposures.

\section{2b. ii. Wireline Log Analysis}

We extend the outcrop-based work with wellbore-based data on rock properties of sonic response (elastic moduli) and gamma ray (GR) signatures (lithology response). We observe $V_{p}$-to- $V_{s}$ relationships within our control wells over specific GR values that are comparable to those established by previous workers for specific lithologies and mineralogy [Figure 11 and Table 3; Pickett, 1963; Castanga et al., 1985, Ellis and Singer, 2007]. Evaluation of the Navajo Sandstone and Carmel Formation in two Drunkards Wash wells show three clear $V_{p}$-to- $V_{s}$ relationships that are grouped by their GR value ranges, with GR serving as proxy for lithology. This suggests that $V_{s}$ can be derived from the $V_{p}$ data based on $G R$ values [Figure 11]. The $V_{p}$-to- $V_{s}$ relationships coded by their GR groups, from the control well Utah D7, exhibit similar groupings in the Utah D8 borehole [Figure 11]. The GR values of less than $50 \mathrm{API}$ and a $\mathrm{V}_{\mathrm{p}^{-}}$ to- $V_{s}$ relationship of 1.9 are characteristic of the argillaceous limestone and limestone facies of the Carmel Formation. The GR values between 50 and 150 API have a $V_{p}$-to- $V_{s}$ relationship of 1.8 and are characteristic of the fine-grained facies in the Carmel Formation. The GR values less than 50 API, having $V_{p}$-to- $V_{s}$ relationships of 1.6, are characteristic of the Navajo Sandstone [Figure 10]. 


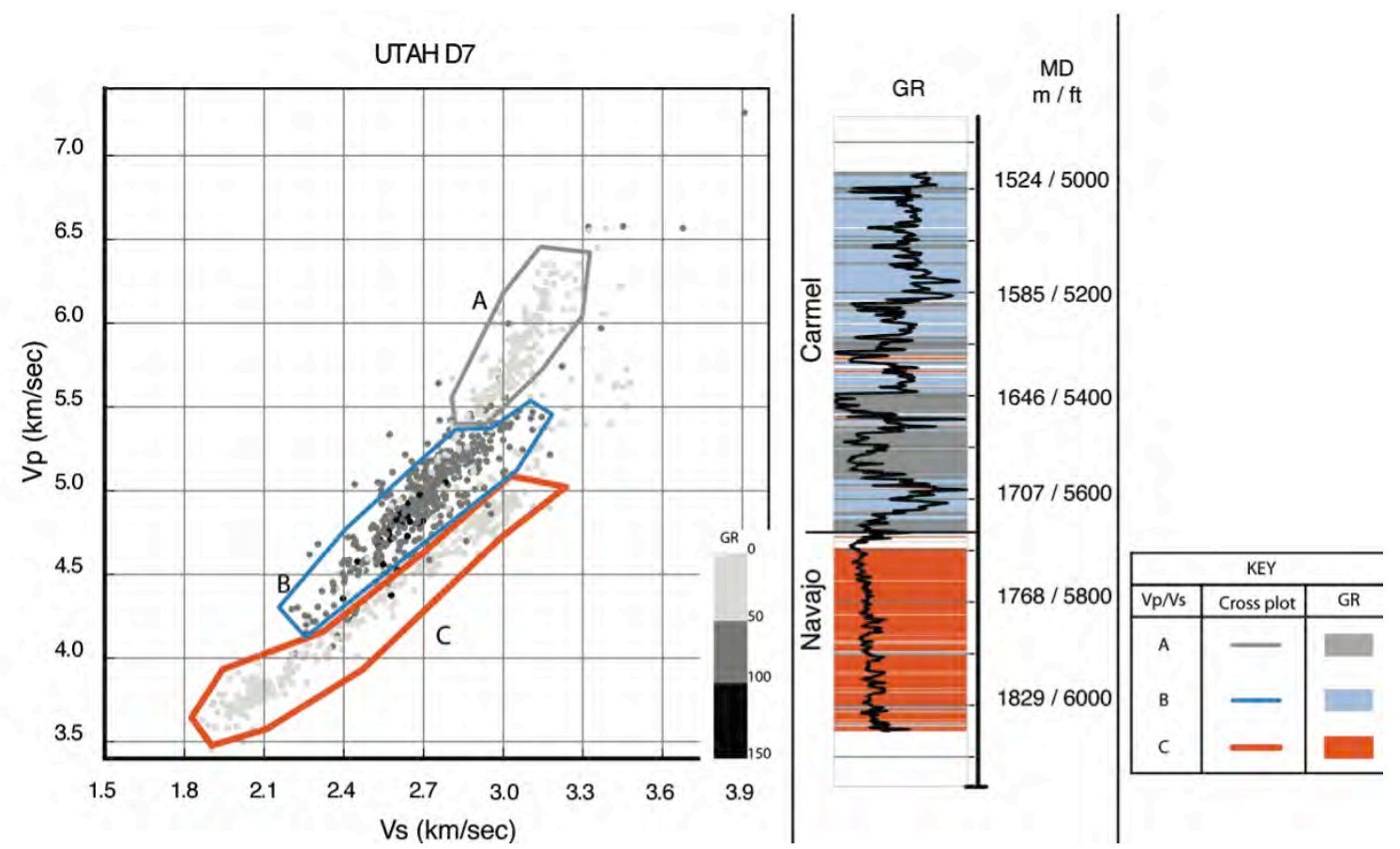

Figure 11. The $\mathrm{V}_{\mathrm{p}}$-to- $\mathrm{V}_{\mathrm{s}}$ relationships coded by their GR groups, from the control well Utah D7.

Table 3.Comparison of $\mathrm{Vp}$-to-Vs relationship from this study and that of previous workers.

\begin{tabular}{|c|c|c|c|c|c|c|}
\hline \multicolumn{9}{|c|}{ THIS STUDY } & \multicolumn{5}{l|}{ PREVIOUS WORKERS } \\
\hline Cross-plot & Gamma Ray & $\mathrm{V}_{\mathrm{p}} / \mathrm{V}_{\mathrm{s}}$ & Lithology & $\mathrm{V}_{\mathrm{p}} / \mathrm{V}_{\mathrm{s}}$ & Mineralogy & $\mathrm{V}_{\mathrm{p}} / \mathrm{V}_{\mathrm{s}}$ \\
\hline $\mathrm{A}$ & $\begin{array}{c}\text { GR< } 50 ; \\
\text { Carmel Formation }\end{array}$ & 1.9 & Limestone & 1.9 & Clay & 2.0 \\
\hline B & $150>\mathrm{GR}>50$ & 1.8 & Dolomite & 1.8 & Quartz & 1.5 \\
\hline C & $\begin{array}{c}\text { GR<50: } \\
\text { Navajo Sandstone }\end{array}$ & 1.7 & Clean Sands & 1.7 & Calcite & 2.0 \\
\hline & GR>150 & 1.5 & Limey Sands & 1.6 & Dolomite & 1.75 \\
\hline
\end{tabular}

Given the relationships observed in our control wells and the consistency of this relationship with those previously published (Pickett, 1963; Castanga et al. 1985, Ellis and Singer, 2007), and our ability to replicate $V_{s}$ data from $V_{p}$ log data [Figure $8 A$ ], we derive an estimate of shear velocity from $V_{p}$ and in turn calculate dynamic values for Poisson's ratio and Young's modulus for the rocks from compressional velocity wireline log data alone. Operations used to derive $V_{s}$ from $V_{p}$ values and elastic moduli are given in Appendix 3 of Petrie et al. (2012). The calculation of shear velocity from compressional velocity in the control wells at Drunkards Wash resulted in no greater than 3\% difference in the Carmel Formation and a difference of less than $4 \%$ in the Navajo Sandstone between values derived directly from dipole sonic log measurements and those calculated using the observed $V_{p}$-to- $V_{s}$ and GR relationships [Figure 12a]. The linear relationships used in the calculations of shear velocity results in Poisson's ratio displaying an average value over each GR interval [Figure 12B]. Dynamic Young's modulus in the basal $10 \mathrm{~m}$ of the Carmel Formation in Celsius Fed 8-1 show variability from 5 to $34 \mathrm{GPa}$ at the meter scale and across interfaces within the Carmel Formation [Figure 12B]. The calculated values for dynamic Young's modulus in all wells results in a median value of $27.9 \mathrm{GPa}$ and a mean value of $27.7 \mathrm{GPa} \pm 6.6 \mathrm{GPa}$. Outcrop observations show that these boundaries have variable fracture connectivity, fracture density and rock strength across stratigraphic boundaries. These observations suggest that variability in fracture distribution and propagation morphology is the result of changes in elastic moduli across stratigraphic interfaces due to changes in the local stress concentrations at/across stratigraphic interfaces. 


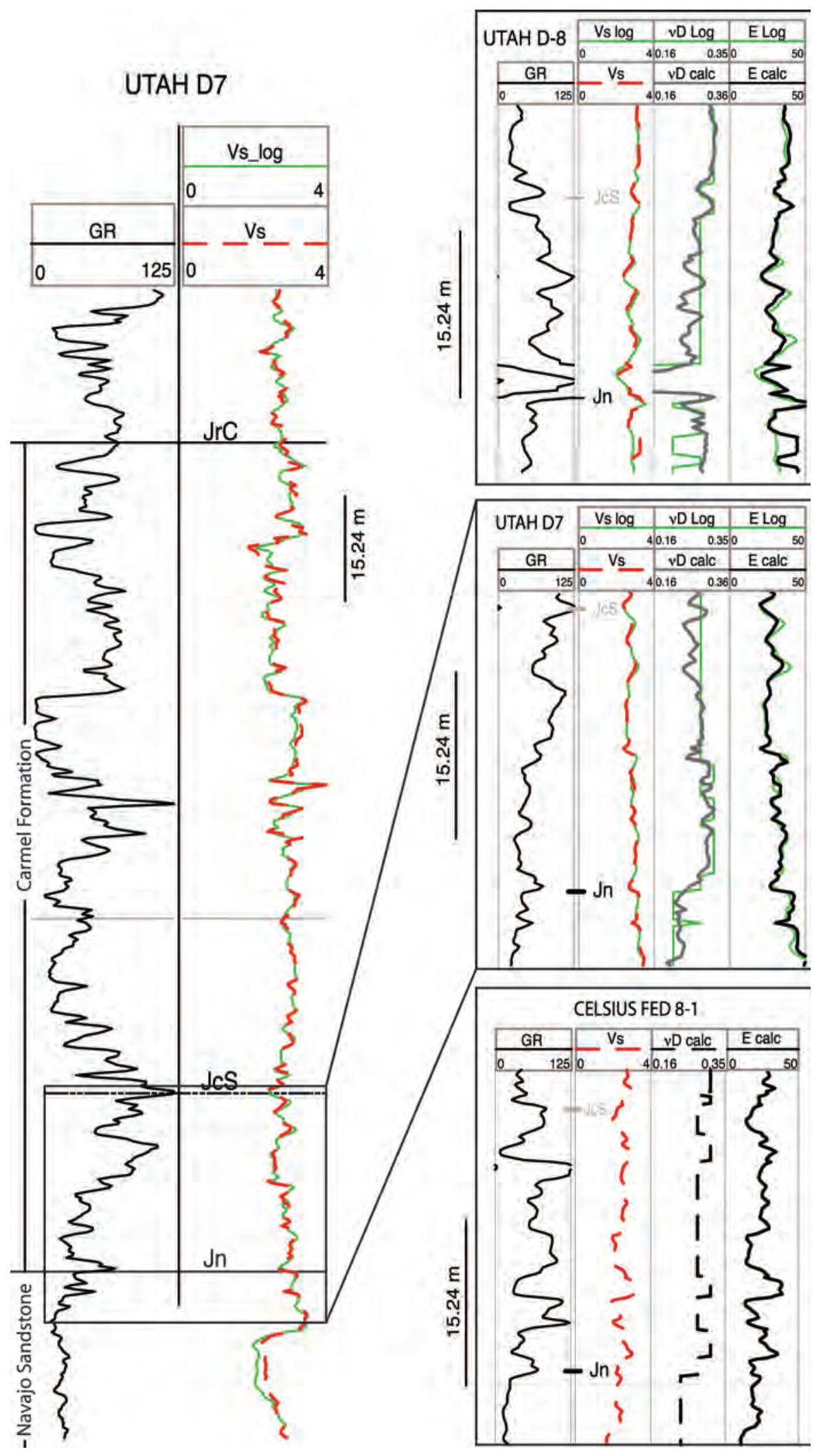


Figure 12. Results of wireline log based elastic moduli calculations. A) Vs_Log is measures shear velocity from dipole sonic, Vs is calculated shear velocity B) Comparison of elastic moduli derived from control wells and closest borehole to outcrop location ( $5 \mathrm{~km}$ southeast of borehole).

The changes in dynamic Young's modulus across the reservoir/seal interface, calculated as the difference in the average dynamic Young's modulus over $0.61 \mathrm{~m}(2 \mathrm{ft})$ on either side of the contact, ranging from 1 to $12 \mathrm{GPa}$, is relatively low when compared to shifts of up to $40 \mathrm{GPa}$ in dynamic Young's modulus observed across intra-seal interfaces [Figure 13]. The difference in dynamic Young's modulus across intra-seal interfaces can range as low as $0.04 \mathrm{GPa}$ and as high as $22 \mathrm{GPa}$, when averaged over lithologic units. When peak to peak shifts, (i.e. minimum to maximum Young's modulus values), across the lithologic units are evaluated larger ranges in dynamic Young's modulus exist within each borehole and range from 0.07 to $40 \mathrm{GPa}$. [Figure 13].

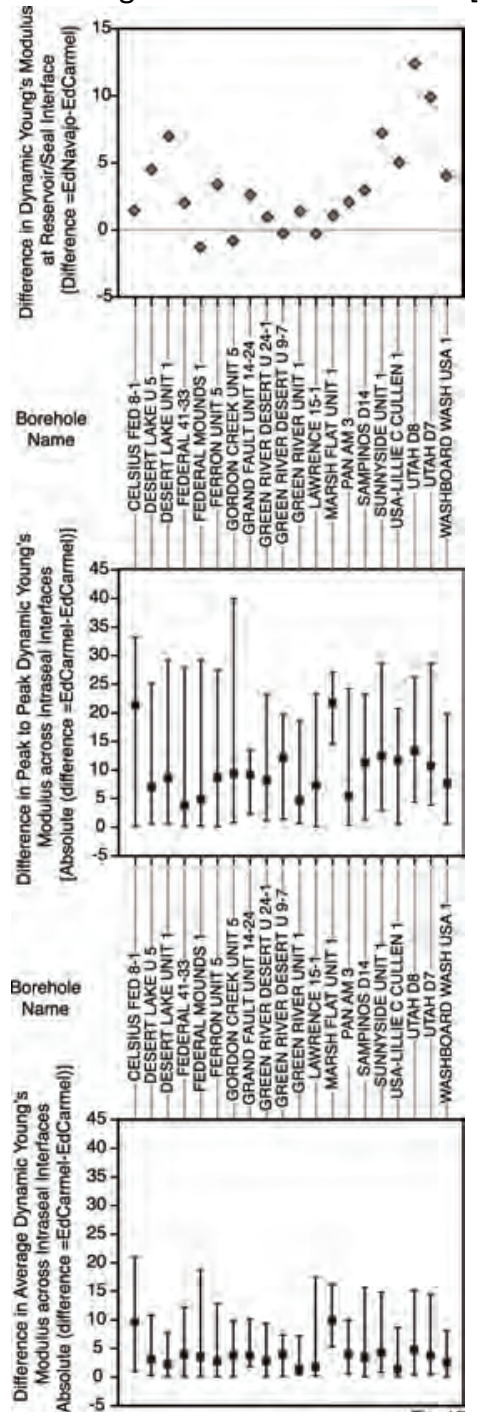

Figure 13. Difference in dynamic Young's modulus across the reservoir seal interface, top, intraseal peakto-peak, center, and across intraseal interfaces, bottom.

Previous research has explored the influence of different types of lithologic interfaces on fracture morphology, termination, step-over or propagation (Cooke and Underwood, 2001; Larsen et al., 2010). Cooke and Underwood (2001) used outcrop analysis and numerical modeling to show that, at a moderate-strength interface, one that is moderately cemented or bonded, fractures will terminate or produce a step-over fracture; very weakly bonded contacts cause termination and strong contacts result 
in propagation across a boundary. We observe step-over fractures with and without bifurcation as well as termination and continuation of fractures at bedding interfaces within this outcrop. Two distinct fractures sets were observed in this study, one associated with deformation and fluid flow in the subsurface and the other linked to exhumation. Mechanical twins have been observed in the calcite veins of some of the fractures, which establish the presence of open fractures that have been mineralized at depth. Fracture density distribution data shows the expected relationship of higher fracture densities associated with thin beds, resistant lithologies and adjacent to small offset (cm-scale) faults.

Flores [2013] used micro- to meso-scale methods to test several hypotheses regarding transmissive fracture distributions near the interface of the Navajo Sandstone and the Carmel Formation. The methods include fracture population mapping and petrographic analysis. Techniques for fracture population mapping include traditional scan line measurements and Sirovosion, modeling software that produces an orthorectified 3-D image from which fracture and fault spacing and orientation can be extrapolated. Micro-scale techniques include petrography with analyses made in Image J and Adobe Photoshop to assist in point counts and determination of structural diagenesis.

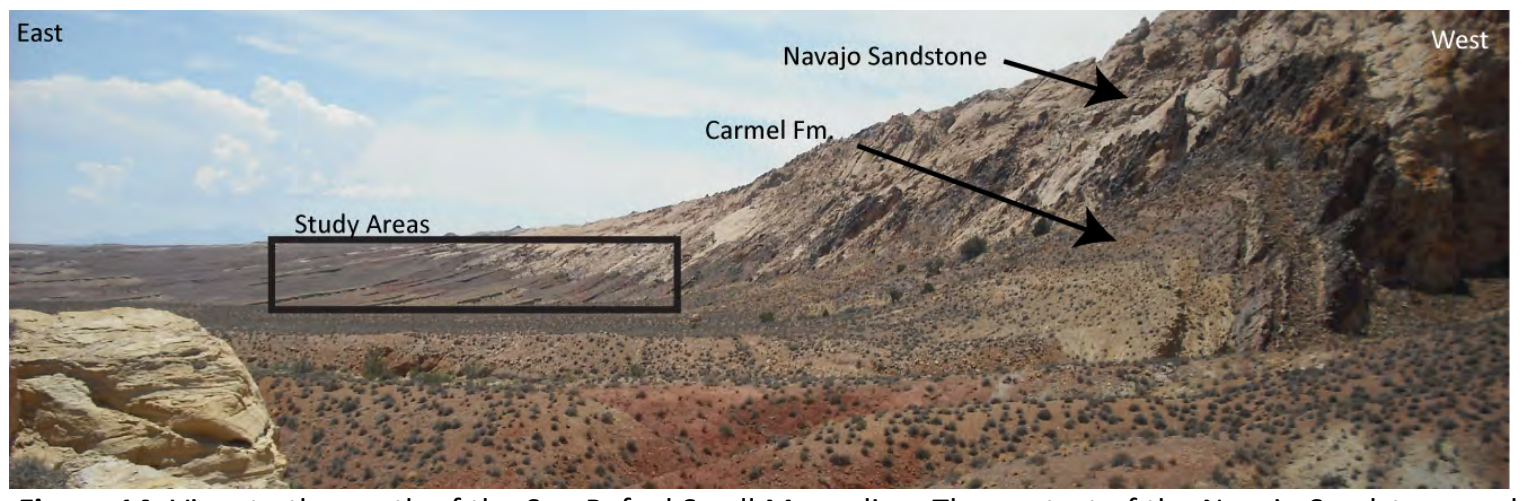

Figure 14. View to the south of the San Rafael Swell Monocline. The contact of the Navajo Sandstone and the Carmel Formation is exposed on the steep, east-dipping limb, as well as near the syncline hinge. The location of some scan line sites and study areas are located in the black box.

Structural setting greatly influences fracture spacing and orientation. Three structural settings were examined and include fault proximity, a fold limb of constant dip (curvature $=0$ ), and a setting proximal to the syncline hinge (curvature $\neq 0$ ) as shown in the black box in Figure 14. Fracture spacing and dominant fracture orientation vary at each setting and distinctions between regional and local paleostress directions can be made. Joints on the fold limb strike normal to the fold axis/bedding and are interpreted to be sub-parallel to the maximum regional paleo-stress direction as there is no fold related strain. Joints proximal to faults and the syncline hinge may have formed under local stress conditions associated with folding and faulting, and in some cases, are perpendicular to the maximum regional paleo-stress direction [Figure 15]. 
Petrographic analyses suggest that permeable fractures at each of the structural settings formed at depth. Mechanical calcite twins and microcrystalline quartz cement are observed on some fracture walls in thin section. The mechanical calcite twins form when the calcite crystal is stressed, and the precipitation of microcrystalline quartz occurs at relatively high temperatures. The combination of mechanical calcite twins and high temperature precipitation of microcrystalline quartz is suggestive of fluid transmission through the fractures in the subsurface, potentially allowing seal-bypass to occur.

Figure 15. Structural contour map of the Navajo Sandstone with scan line locations on the left with fracture orientation data for the Navajo Sandstone (Jn) and Carmel Formation (Jc) plotted on the right. Fracture orientations near N40W are interpreted to be from paleo-regional stress, and orientations 口

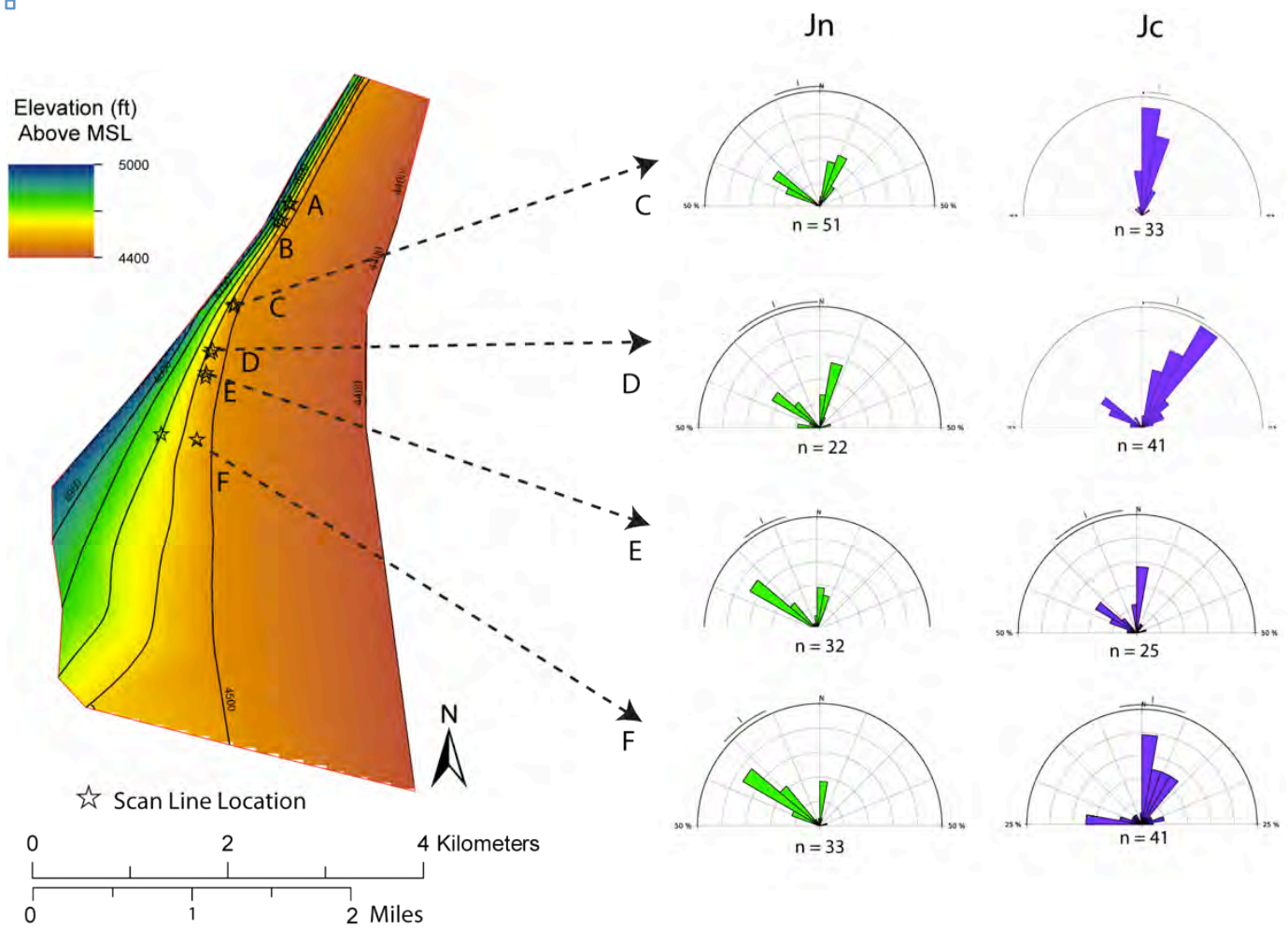

plotted between $\mathrm{N}$ and $\mathrm{N} 45^{\circ} \mathrm{E}$ are interpreted to be from local, fold related stress near the syncline hinge.

Petrie et al. (in press) evaluate the nature of a mineralized fault damage zone associated with a reactivated long-strike length, small-offset normal fault in the Permian Cedar Mesa Sandstone, southeastern Utah in order to evaluate the role that meso-scale faults and fracture zones may play on fluid flow. The faults are characterized by a single slip surfaces and up to 9-m wide damage zone containing deformation bands, veins, and joints. Field observations include crosscutting relationships, permeability measurements, rock strength values, and a novel ultraviolet-light induced mineral fluorescence within the damage zone. These observations combined with the interpreted paragenetic sequence from petrographic analysis to suggest a deformation history of reactivation and several mineralization events in an otherwise low-permeability fault.

Mineralization associated with the faults include hematite veins, liesegang banding are adjacent to the main slip-surface, and calcite veins ubiquitous in the damage zone of the fault. Scanline data reveal an increase in fracture density adjacent to the fault [Figure16]. Digital photographs taken of outcrops illuminated under a UV light source highlights the connectivity between fractures of all orientations and the extensive mineralization of both joint sets that is not obvious in visible light [Figure 16]. The yellow to white UV-induced fluorescence response occurs in the calcite vein minerals as well as calcite-cored deformation bands. The presence of uranium in calcite causes a yellow/white fluorescence when exposed to UV light (Wenk and Bulakh, 2004). The UV-induced fluorescence does not occur away from the fault damage zone. 

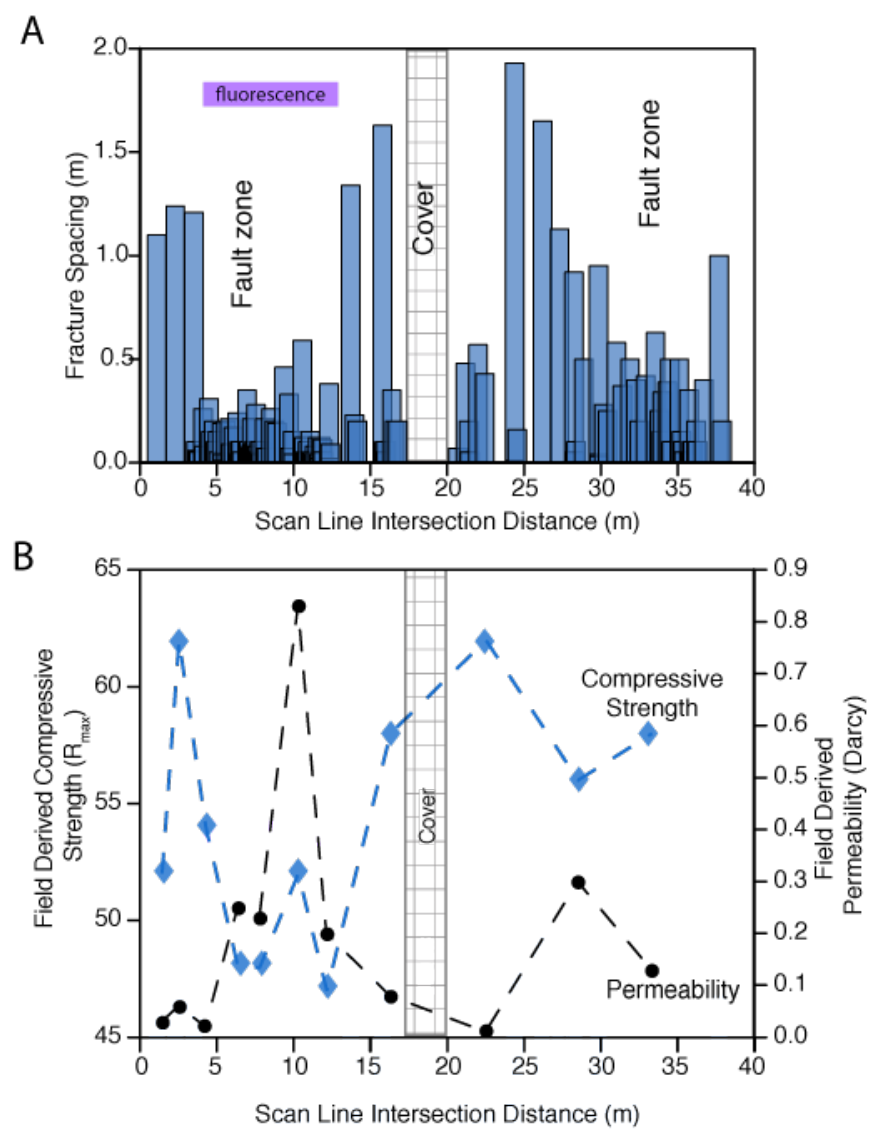

Figure 16. Scanline data in the Cedar Mesa Sandstone, A) fracture spacing (distance between fractures) is decreased in and adjacent to the fault zone; B) Compressive strength decreases and permeability increases in and adjacent to the fault zone.

The observed UV-induced fluorescence response is coincident with the occurrence of increased fracture densities; increased field derived air permeability and decreased rock strength (Figure 16B). Based on these field observations we estimate that the fault damage zone is $9 \mathrm{~m}$ in width (Figure 16). Because the observed UV-induced fluorescence occurs in fractures of all orientations we use petrography and trace- element geochemistry and to evaluate the paragenetic sequence and define the deformational history of this fault damage zone.

Petrographic observations are used in conjunction with field observations help establish a structural paragenetic sequence. These petrographic observations include quartz overgrowths, diffusive mass transport features (DMT), crosscutting relationships, mineral occurrence, mineral morphology, and evidence for cataclastic deformation. The sandstone protolith shows no evidence of deformationenhanced diagenesis; it has rare DMT features and rare inter-granular calcite cement. Quartz overgrowths are common in host rock samples; quartz overgrowths often encase hematite rims around the original quartz clasts and are interpreted to have occurred early in the paragenetic sequence [Figure 17A]. Quartz overgrowths are followed by the development of DMT features; DMT features lack hematite at the grain contacts. The Cedar Mesa Sandstone in other localities is red due to the presence of hematite cement (Mountney and Jagger, 2004). Quartz overgrowths occurred early in the diagenetic sequence followed by alteration and/or removal of hematite cements prior to formation of DMT features. Based on the observed mineralogy, presence of relict clasts in the veins, and crosscutting relationships between veins we propose several phases of vein mineralization. Adjacent to large veins micro-cracks are filled with either hematite or calcite [Figure 17B], the micro-crack mineralization can differ from that of wider, adjacent vein and supports the hypothesis of a varied sub-surface fluid flow and mineralization history. 
Calcite veins show a minimum of two phases of mineralization with symmetric euhedral calcite crystals at the interface with the sandstone host rock and a core of aragonite [Figure 17C]. All thin-sections containing calcite vein fill respond to UV light exposure, as both transmitted and reflected UV light. Hematite veins are cross cut by later calcite/aragonite minerals at an acute angle of 81을igure17D].
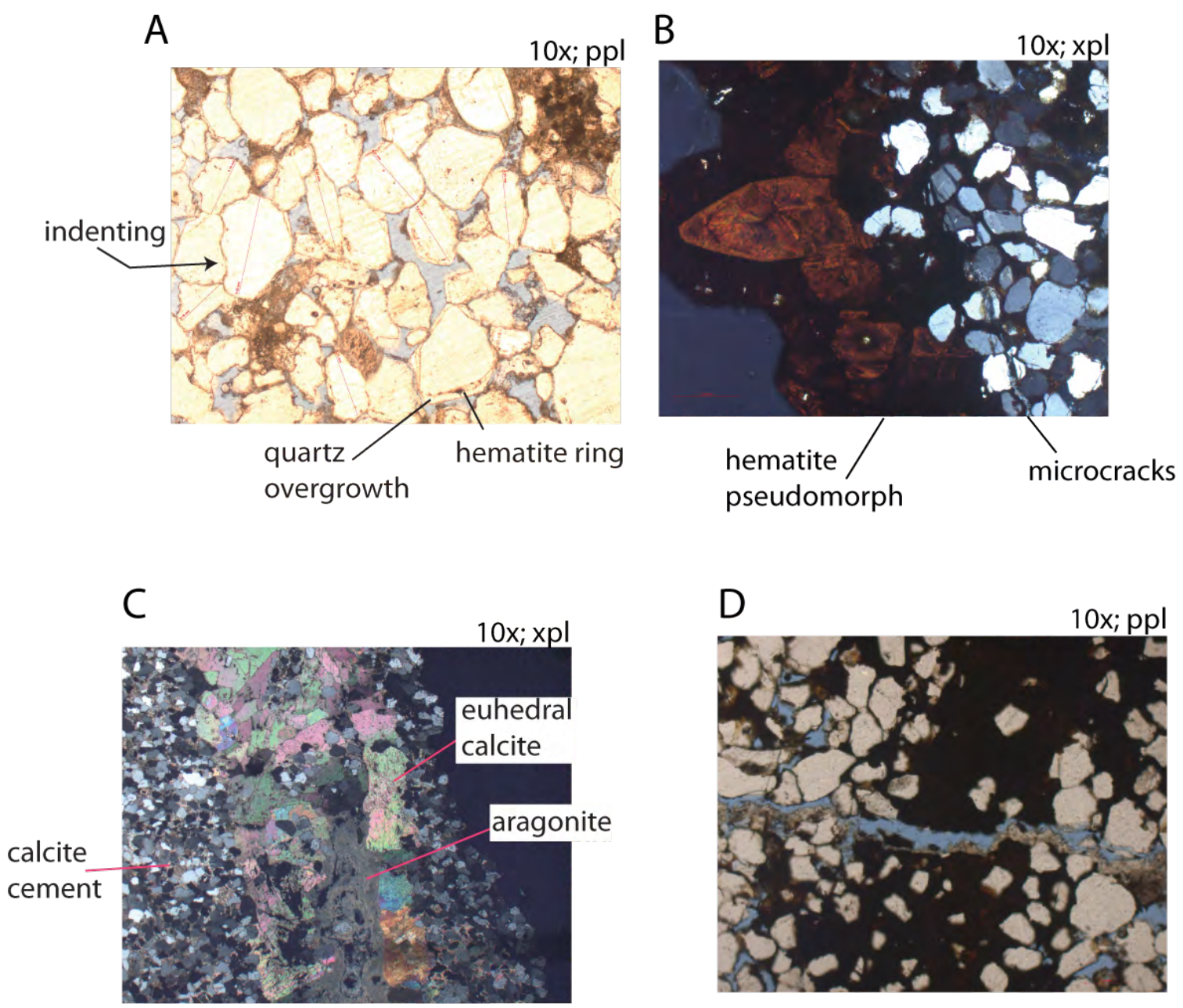

calcite vein cutting hematite vein

\section{$0 . \overline{25 \mathrm{~mm}}$}

Figure 17. Photomicrographs showing structural and fluid flow alteration features from the Cedar Mesa Sandstone damage zone.

Evidence for reactivation and enhanced permeability within this fault damage zone highlights the complex nature of deformation bands and fractures adjacent to the faults examined here in the Cedar Mesa Sandstone. Small-scale pre-existing structural discontinuities provide loci for nucleation of future deformation as well as a zone of enhanced permeability over a wide area $(9 \mathrm{~m})$ adjacent to the main fault strand. Understanding the complexities associated with small-offset damage zones is critical to understanding fluid flow in sequestration waste in nuclear waste storage or $\mathrm{CO}_{2}$ storage scenarios. This small-offset, long-strike length fault is unique and provides evidence for multiple fluid flow events and dilatancy at moderate confining pressures in fine-grained porous sandstone. 
The presence of hematite and calcite veins, vein-filling minerals (revealed by UV induced fluorescence), increased fracture density, increased field-derived permeability and decreased rock strength characterize the fault damage zone associated with this $25 \mathrm{~km}$ long, small-offset, normal fault. The UV light induced fluorescence occurs in deformation features of all orientations but does not occur outside of the fault damage zone [Figure 16]. Petrographic observations suggest several mineralization events, and these features illustrate the varied and repetitive mineralization history associated with the fault damage zone [Figure 17]. We interpret this mineralization to have occurred in the subsurface, the presence of high Fe concentrations within the calcite veins suggesting precipitation under anoxic conditions. Lack of grain crushing and rotation adjacent to mineralized veins suggest zones of increased porosity and permeability within the damage zone, with moderate cataclasis.

The ability of a fault or fault damage zone to act as a barrier or conduit for fluid flow is controlled by the distribution and connectivity of the fault damage zone components (Knipe, 1993; Caine et al., 1996; Davatzes et al., 2003). In this example we propose that the presence of pre-existing structural discontinuities provide loci for nucleation of future deformation as well as a zone of enhanced permeability, in some places along a fault that would have been characterized as a barrier were it not for the UV studies and the detailed petrologic analyses.

\section{2c. Core Studies}

In order to examine the top seal at near- in situ conditions, we took advantage of a scientific borehole that was drilled into an onshore anticline near the town of Green River, Utah to study a series of natural $\mathrm{CO}_{2}$ reservoirs. We recovered core and $\mathrm{CO}_{2}$-charged fluids from natural $\mathrm{CO}_{2}$ reservoirs and reservoir caprocks in order to study and understand the long term consequences of exposure of $\mathrm{CO}_{2}-$ gases and $\mathrm{CO}_{2}$-charged fluids on geological materials, to improve our predictions of the security of future geological $\mathrm{CO}_{2}$ storage sites. The well $\mathrm{CO} 2 \mathrm{~W} 55$ was spudded into the footwall of the Little Grand Wash normal fault at the apex of the Green River anticline, near the site of Crystal Geyser, a large cold-water $\mathrm{CO}_{2}$-driven geyser [Figure 18]. The well first encountered $\mathrm{CO}_{2}$ charged fluids at $\sim 80 \mathrm{~m}$ depth, in the basal sandstones of the Entrada Sandstone, which is open to surface, the fluids being effectively sealed by thin siltstone layers within the sandstone unit. The well penetrated a $\sim 20 \mathrm{~m}$ thick fault zone within the Carmel Formation, the footwall damage zone of which hosted $\mathrm{CO}_{2}$-charged fluids in open fractures. $\mathrm{CO}_{2}$-rich fluids where encountered throughout the thickness of the Navajo Sandstone, which has been locally bleached white by removal of oxide grain coatings by contact with the $\mathrm{CO}_{2}$-rich fluids. Fluid samples were collected from the Navajo Sandstone at formation pressures using a specialized downhole wireline sampler, and fluid $\mathrm{CO}_{2}$ content and $\mathrm{pH}$ were measured at surface using a high-pressure apparatus. Exsolution of $\mathrm{CO}_{2}$ gas from the formation fluid during retrieval of the core barrel to surface lead to gas build-up within the well bore, causing rapid ejection of the barrel, which lead to challenging drilling conditions. 


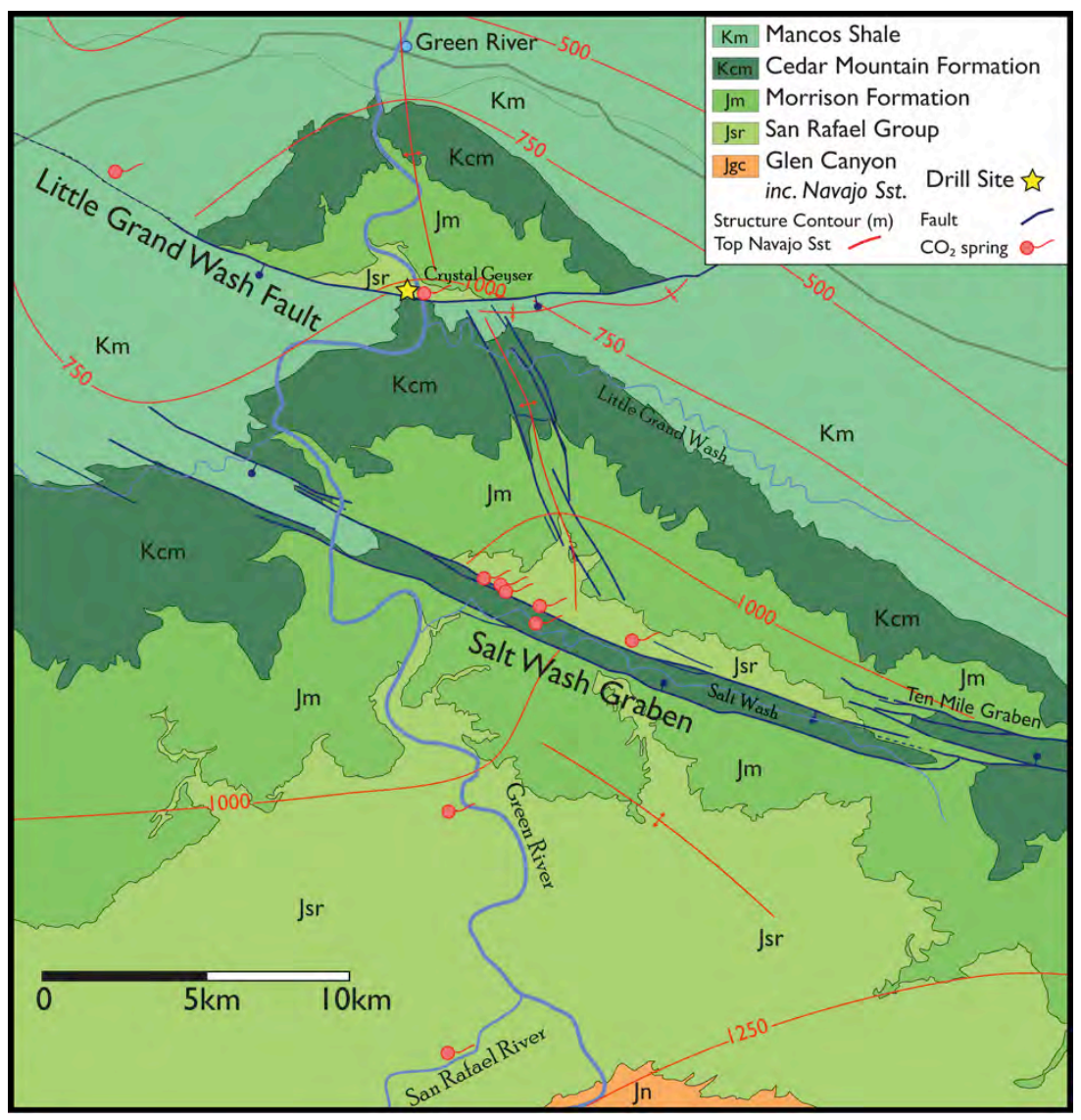

Figure 18. Geological map of the Green River anticline showing locations of the Little Grand Wash and Salt Wash Graben normal fault systems, $\mathrm{CO}_{2}$-springs and location of drill hole $\mathrm{CO} 2 \mathrm{~W} 55$. Structure contours are for the top surface of the Navajo Sandstone, the main $\mathrm{CO}_{2}$ bearing reservoir.

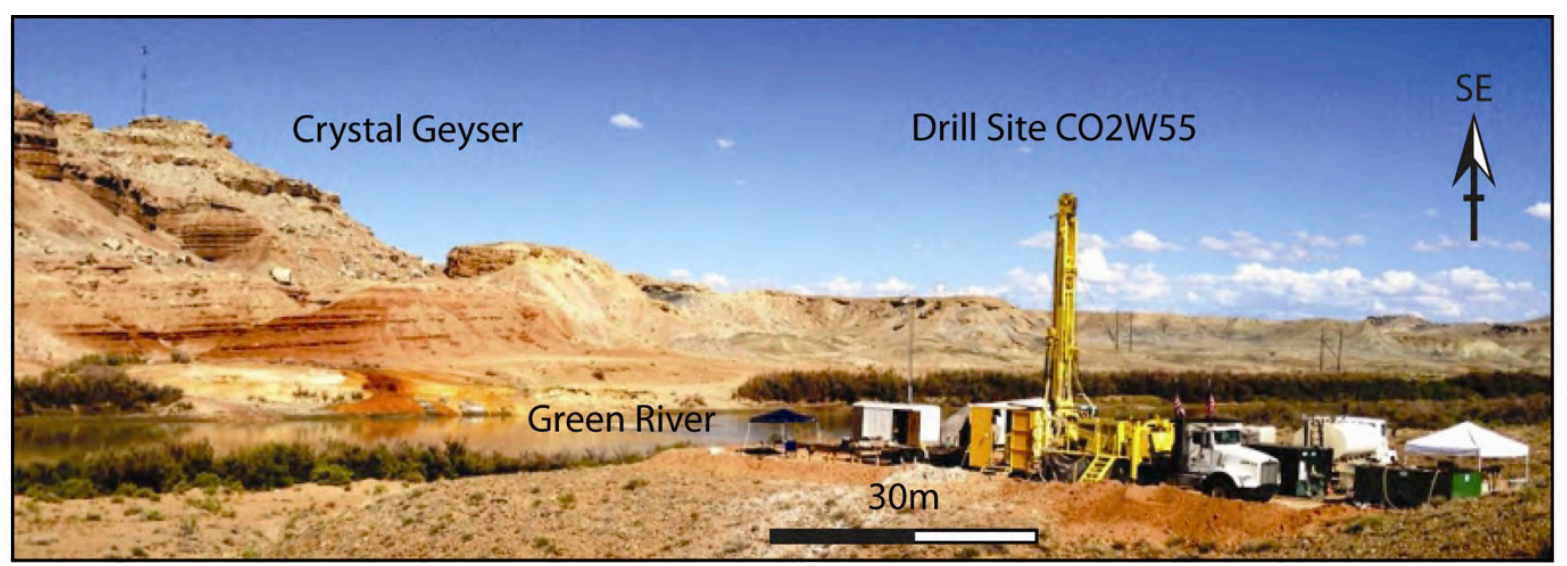

Figure 19. Field photograph of the drill site of well CO2W55 showing the CS4002 Truck Mounted Core Drill in the foreground and the travertine mound formed by Crystal Geyser on opposite bank of the Green River. 


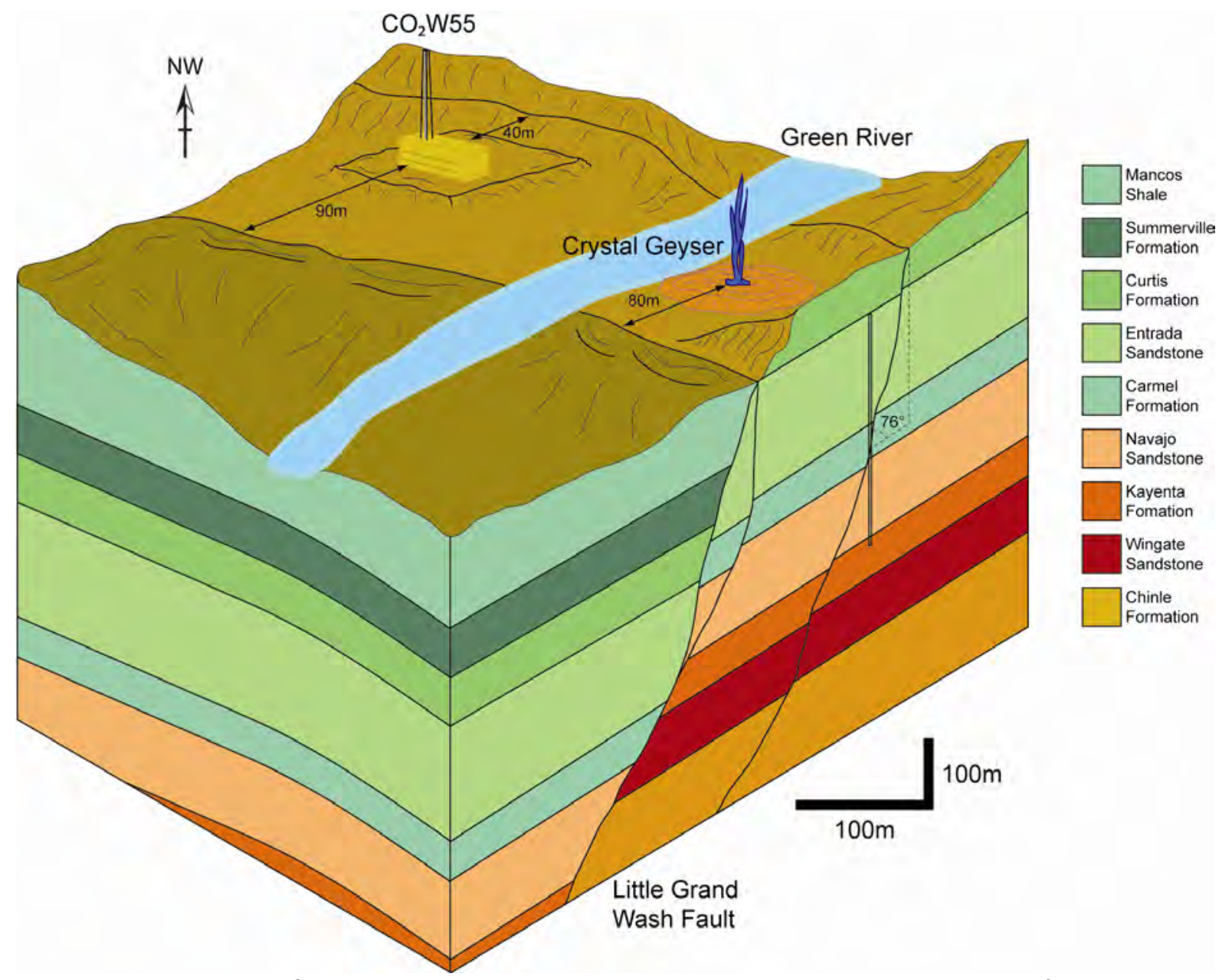

Figure 20.Cross section of the region surrounding drill hole CO2W55 showing the location of the Little Grand Wash fault system, including the northerly fault transacted by the drill hole (limited exposure precluded mapping this at surface), and the $\mathrm{CO}_{2}$-driven cold water geyser at Crystal Geyser.

The hole was drilled vertically to a depth of $322.5 \mathrm{~m}$ using DOSECC's hybrid coring system, with core recovery close to $100 \%$. On site processing of the core involved core description, photographing and selective bagging of important core sections 

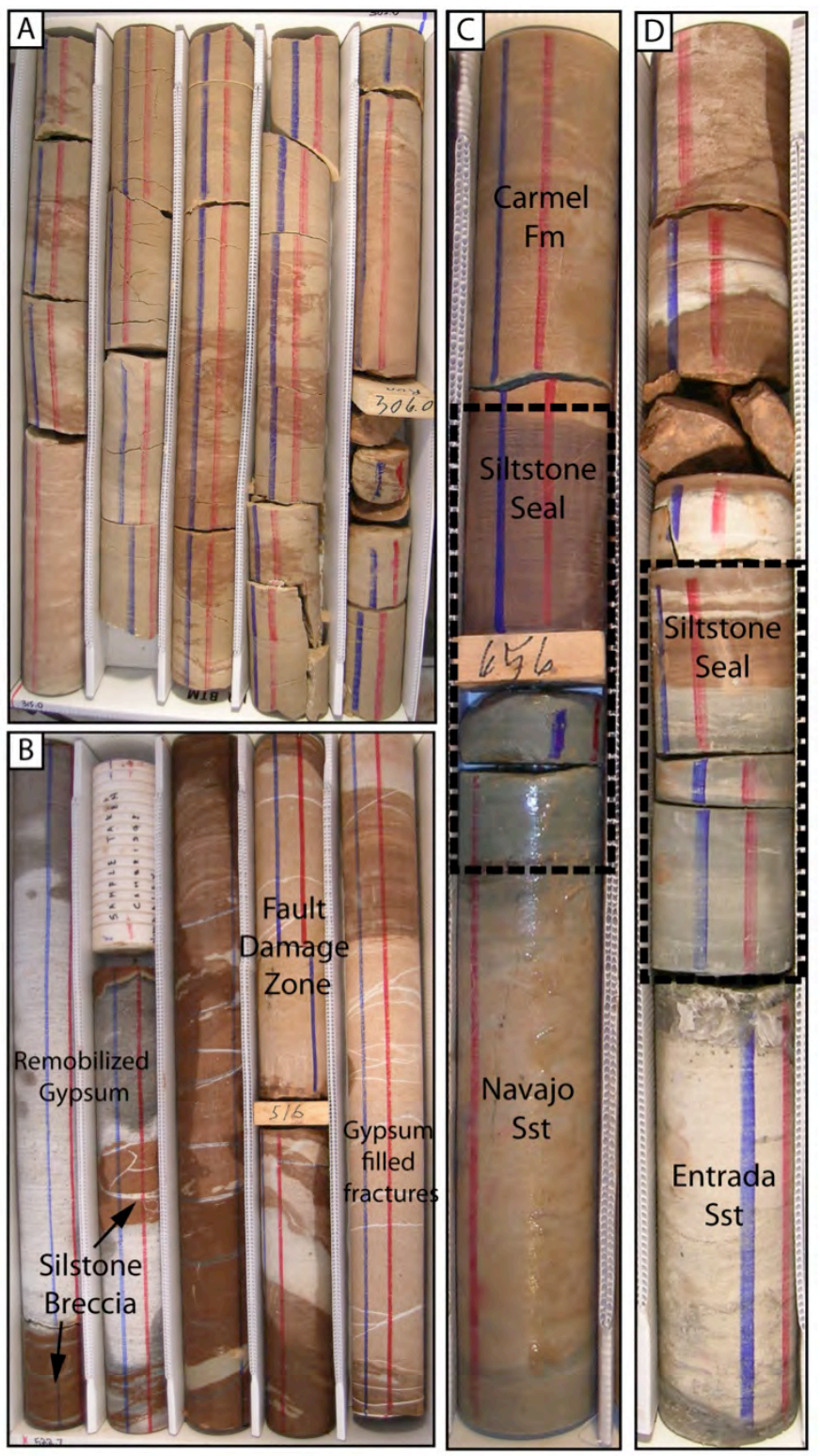

Figure 21.(A) Bleached basal sandstones of the Entrada Sandstone hosting $\mathrm{CO}_{2}$ charged fluids. Fracturing of the core occurs at surface due to exsolution of $\mathrm{CO}_{2}$ gas from the fluids held in core porosity. The relative permeabilities of water and gas result in a build up of gas within the pore space, which expands causing the cores to break apart. (B) Sections of the fault core and damage zone from the Carmel formation showing fractured blocks of siltstone residing in remobilized gypsum horizons and pervasive fracturing of the core in the footwall fault damage zone. (C) and (D) Siltstone-sandstone contacts from $\mathrm{CO}_{2}$-hosting sections of the Entrada and Navajo Sandstones showing bleaching and alteration of the originally red siltstones over a $10 \mathrm{~cm}$ distance by diffusion of $\mathrm{CO}_{2}$ into the reservoir caprocks.

From the surface to $25 \mathrm{mbs}$, marine and lacustrine red siltstones facies of the 'Earthy' Entrada Sandstone member grade into the $125 \mathrm{~m}$-thick bleached aeolian dune deposits of the lower Entrada Sandstone, with intercalated marginal marine and sabkha influences throughout. Surprisingly, the drill hole encountered pressurized water in the sand-rich Entrada. The Entrada is exposed at the surface just 1 $\mathrm{km}$ away, and our hypothesis would be that pressurized shallow groundwater would flow to the exposed surface outcrop of the sandstone. 
Below the Entrada lies the Carmel Formation a 50 m-thick complex package consisting of four laterally gradational lithofacies, including shale, bedded gypsum, mudstone/siltstone, and fine-grained sandstone. These are interpreted as marine sediments deposited in quiet, subtidal conditions under the influence of periodic hypersaline water. Extensional faulting within the recovered interval has resulted in the formation of an $\sim 20 \mathrm{~m}$ thick fault zone comprising a $\sim 9 \mathrm{~m}$ thick fault core containing meter scale blocks of siltstone and shale breccia hosted in remobilized gypsum beds. These are bound by a fault damage zone of gypsum-filled open fractures, of $\sim 2 \mathrm{~m}$ thick in the hangingwall and $\sim 9 \mathrm{~m}$ thick in the footwall. The fracture zone in the footwall block was found to be transmissive, and surface returns of reservoir fluids were sampled. The Carmel Formation forms a regional seal for the underlying Navajo formation (Peterson and Turner-Peterson, 1989). In Green River core CO2W55 the $\mathrm{CO}_{2}$-charged Jurassic Navajo Sandstone is a homogenous unit comprising thick sets of high-angle cross-bedded, well-sorted, fine- to medium-grained sandstone with internal stratification. The unit is extensively bleached from its typical red, to pale pink and white from the dissolution of hematite grain coatings by $\mathrm{CO}_{2}$-charged fluids c.f. (Wigley et al., 2013a; Wigley et al., 2013b; Wigley et al., 2012). The lower portions $(5-10 \mathrm{~cm}$ 's) of many of the sealing siltstone layers in the Entrada and Carmel formations are also bleached where they are in contact with $\mathrm{CO}_{2}$-hosting reservoir sandstones, suggesting penetration of $\mathrm{CO}_{2}$ by diffusion and alteration of the caprock mineralogy, accompanied by the extensive precipitation of carbonate minerals.

The water in the Jurassic Navajo was also pressurized by $\mathrm{CO}_{2}$. High water pressures that exceeded the drillers' ability to maintain mud weight suggest that $\mathrm{CO}_{2}$ was exsolving from solution [Kampman et al., submitted]. Further analyses of the core [Figure 21] are underway.

\section{2d. Laboratory Analysis}

Many of the laboratory analyses results are discussed above in the context of paragenesis, microscopic observations, and mineralogy. In addition, we have collaborated with Sandia National Laboratories Rock Mechanics lab under the direction of Dr. Steven Bauer. Samples are still being examined as of this report.

\section{2e. Data Analysis and Model Building}

The abundant data acquired in outcrop, from core, and from well log data can be used to populate numerical models of deformation using finite element analysis in the student version of Abaqus. Using the combined data sets from outcrop and wireline well logs, Petrie [2013] populated mechanical models with elastic properties averaged over the meter scale while our outcrop observations are used to delineation broad mechano-stratigraphic units [Figure 22A \& Table 4].

The model scenarios created to date have been used to replicate at-depth stress conditions and show the strain distribution and deformation magnitude of the layered material. We evaluate the effect changing values of Young's modulus to understand at the effect of averaging elastic moduli over the meter-scale has on the distribution of strain and subsequently deformation. We consider a uniaxial strain model, and create 3D solids with the following dimensions; length $5 \mathrm{~m}$, total height $10 \mathrm{~m}$, and depth $2 \mathrm{~m}$. Each scenario has one fixed vertical margin, representing a far field stable horizontal stress; a vertical pressure of $22.2 \mathrm{MPa}$ representing and estimate of lithostatic load at maximum burial depth, and a horizontal pressure of $13.7 \mathrm{MPa}$ representing minimum horizontal stress, the base of the model is a free surface [Figure 22A]. The physical properties (layer thickness and Young's modulus) are varied within each scenario as listed in Table 4. 
Table 4. Model parameters.

\begin{tabular}{|l|c|c|c|}
\hline \multicolumn{1}{|c|}{ Layer Properties } & Layer number & $\begin{array}{c}\text { Unit thickness }(\mathbf{m}) \\
\text { \{Cumulative thickness } \\
\text { defines height }\end{array}$ & Young's Modulus (GPa) \\
\hline $\begin{array}{c}\text { Model 1 } \\
\text { Simple stack }\end{array}$ & $1-3$ & 2.0 & 30 \\
$\begin{array}{l}\text { Outcrop mechano- } \\
\text { stratigraphic unit based }\end{array}$ & $1-2$ & 6.0 & 7 \\
\hline Model 2 & $1-1$ & 2.0 & 33 \\
6 layer & $2-6$ & 1 & 17 \\
Outcrop mechano- & $2-5$ & 1.25 & 24 \\
stratigraphic units and & $2-4$ & 2.75 & 27 \\
wireline log shifts based & $2-3$ & 1 & 17 \\
& $2-2$ & 1.25 & 18 \\
\hline
\end{tabular}

Both models show a high strain value in the high Young's modulus values (i.e. stiff material) at the top of block, strain values decrease with depth. Although no significant difference in strain magnitude is noted between the two models (Table 5), we do observe distinct differences in strain distribution. We note that the strain distribution is more widespread in model 1 , and we that the strain discontinuity plot shows noticeable boundaries between the mechanical layers. In model 2 strain distribution and boundaries are more diffuse. The added complexity of model 2, which is based on a combination of mechano-stratigraphy observed in outcrop and variability observed in wireline logs results, indicate that combination of these two data types will result in a more even strain distribution, suggesting that in the case of rock failure discontinuities could propagate across boundaries. The discontinuity results of model 1 on the other hand suggest that the thicker layers of consistent material may result in fracture termination and local accumulation of strain at the material boundary interface.

Table 5. Range of maximum principal strain values for each scenario. Model 1 Maximum principal strain:

\begin{tabular}{|l|l|l|}
\hline & Load $--S_{h}$ & Load $--S_{V}$ \\
\hline Field Output & $2.4 \times 10^{-4}$ to $1.4 \times 10^{-3}$ & $3.9 \times 10^{-6}$ to $1.9 \times 10^{-3}$ \\
\hline Discontinuities & 0 to $8.6 \times 10^{-4}$ & 0 to $9.3 \times 10^{-4}$ \\
\hline
\end{tabular}

Model 2 Maximum principal strain:

\begin{tabular}{|l|l|l|}
\hline & Load -- $S_{\mathrm{h}}$ & Load -- $\mathrm{S}_{\mathrm{v}}$ \\
\hline Field Output & $1.5 \times 10^{-4}$ to $8.2 \times 10^{-4}$ & $6.2 \times 10^{-6}$ to $1.3 \times 10^{-3}$ \\
\hline Discontinuities & 0 to $6.6 \times 10^{-4}$ & 0 to $7.3 \times 10^{-4}$ \\
\hline
\end{tabular}


A
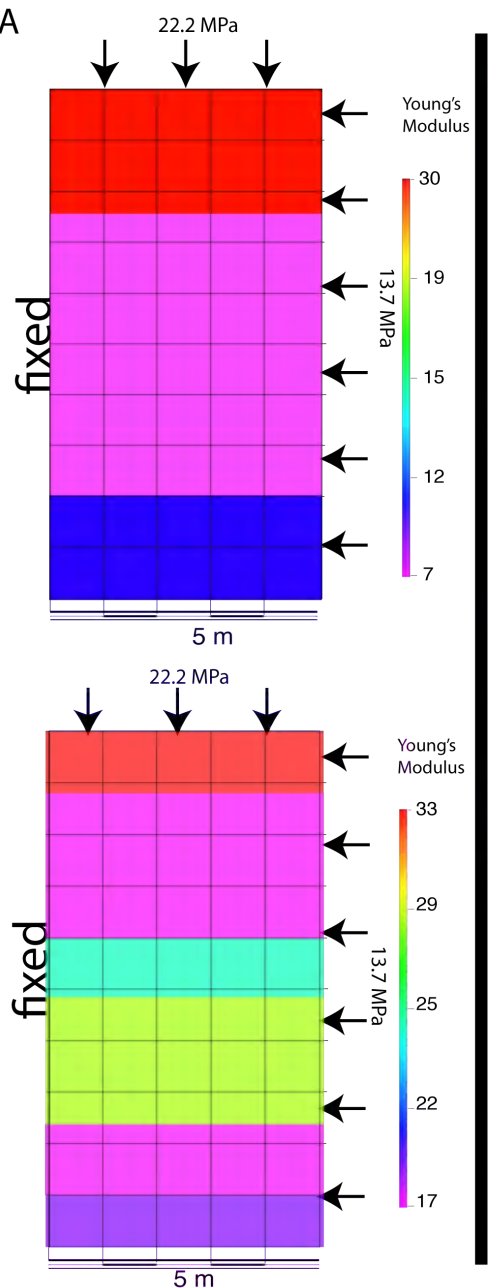

B
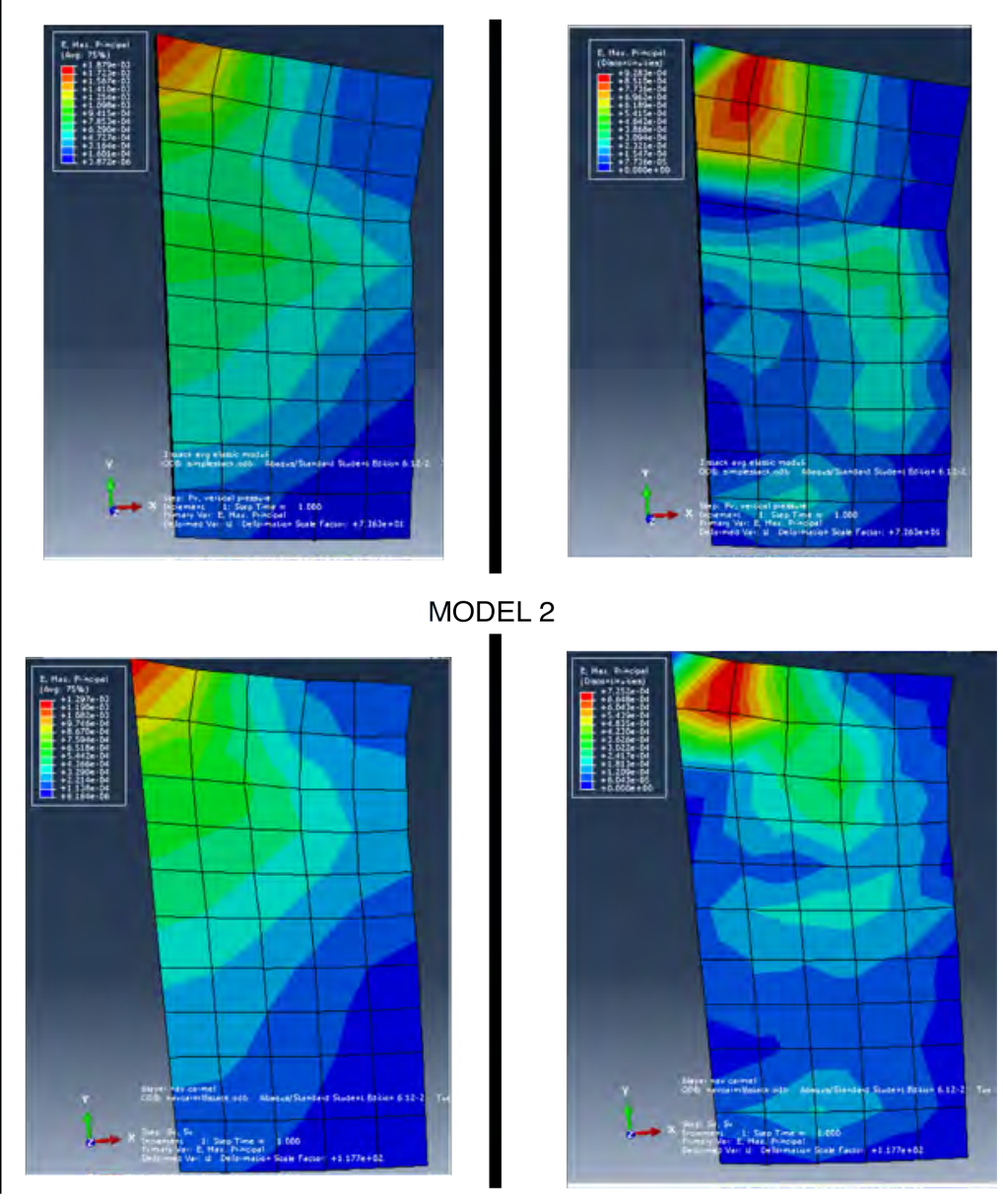

Figure 22.A) Model scenario schematics. B) Model results of Pv (vertical load, pressure 22.2 MPa); on the left average maximum principal strain distribution and maximum principal strain discontinuity on the right.

Currently we are comparing model outputs to observed fracture distribution to understand model consistency with outcrop and core analog. Modeling of other rock type, stratigraphic thickness and stacking scenarios continues and going forward we plan to incorporate permeability and porosity data as well as variation in Poisson's ratio and tectonic stress.

\section{Conclusions}

In this work, we provided education in $\mathrm{CO}_{2}$ systems to four graduate students (Barton, Flores, Petrie, and Richey), and partial support to five undergraduate students. These students have produced a body of work that significantly adds to our understanding of how top seals may act to trap $\mathrm{CO}_{2}$ in the subsurface, and the conditions by which the seal may fail and allow $\mathrm{CO}_{2}$ to escape.

\section{References}

Allis, R. et al., 2001, Natural $\mathrm{CO}_{2}$ reservoirs on the Colorado Plateau and Southern Rocky Mountains:

Candidates for $\mathrm{CO}_{2}$ Sequestration. Proc. Nat. Conf. on Carbon Sequestration. 
Assayag, N., Bickle, M., Kampman, N., Becker, J., 2009, Carbon isotopic constraints on $\mathrm{CO}_{2}$ degassing in cold-water Geysers, Green River, Utah. Energy Procedia, v.1, no. 1, p. 2361-2366.

Baer, J.L., Rigby, J.K., 1978, Geology of the Crystal Geyser and environmental implications of its effluent, Grand County, Utah. Utah Geology, v. 5, p.2.

Barton, D. C., 2011, Determining $\mathrm{CO}_{2}$ storage potential-Characterization of seal integrity and reservoir failure in exposed analogs: Logan, Utah State University, M.S. thesis, 177 p. http://digitalcommons.usu.edu/etd/1118/

Bickle, M.J., 2009, Geological carbon storage. Nature Geoscience, 2: 815-818.

Burnside, N., Shipton, Z., Dockrill, B., Ellam, R.M., 2013. Man-made versus natural $\mathrm{CO}_{2}$ leakage: A 400 k.y. history of an analogue for engineered geological storage of $\mathrm{CO}_{2}$. Geology.

Caine, J. S., Evans, J. P., and Forster, C. B., 1996, Fault zone architecture and permeability structure: Geology, v. 24, p. 1025-1028.

Castanga, J.P., M. L, Batzle, and R. L. Eastwood, 1985, Relationships between compressional-wave and shear-wave velocities in clastic silicate rocks: Geophysics, v. 50, no. 4, p. 571-581.

Clarke, R. M., and Cox, S. J. D., 1996, A modern regression approach to determining fault displacementlength scaling relationships: Journal of Structural Geology, v. 18, no. 203, p. 147-152.

Cooke, M.L. and C. A. Underwood, 2001, Fracture termination and step-over at bedding interfaces due to frictional slip and interface opening: Journal of Structural Geology, v. 23, no.2-3. p. 223-238.

Cowie, P. A., and Scholz, C. H., 1992, Displacement-length scaling relationship for faults-data synthesis and discussion: Journal of Structural Geology, v. 14, no. 10, p. 1149-1156.

Davatzes, N. C., Aydin, A., and Eichhubl, P., 2003, Overprinting faulting mechanisms during the development of multiple fault sets in sandstone, Chimney Rock fault array, Utah, USA: Tectonophysics, v. 363, p. 1-18.

Dockrill, B., Shipton, Z.K., 2010, Structural controls on leakage from a natural $\mathrm{CO}_{2}$ geologic storage site: Central Utah, U.S.A. Journal of Structural Geology, v. 32, no. 11, p. 1768-1782.

Doelling, H. H., 2002, Interim Geologic Map of the San Rafael Desert 30'x60' Quadrangle, Emery and Grand Counties, Utah: Utah Geological Survey Open-File Report v. 104, p, 22.

Ellis, D. V. and J. M. Singer, 2007, Well logging for Earth Scientists, 2d ed., Springer, p. 692.

Evans, J.P., Heath, J., Shipton, Z.K., Kolesar, P.T., Dockrill, B., Williams, A., Kirchner, D., Lachmar, T.E. and Nelson, S.T., 2004, Natural leaking $\mathrm{CO}_{2}$-charged systems as analogs for geologic sequestration sites, Third Annual Conference on Carbon Capture and Seqeustration, Alexandia, VA..

Gouveia, F., Friedmann, S., 2006, Timing and prediction of $\mathrm{CO}_{2}$ eruptions from Crystal Geyser, UT. United States. Dept. of Energy. 
Gouveia, F., Johnson, M., Leif, R., Friedmann, S., 2005, Aerometric measurement and modeling of the mass of $\mathrm{CO}_{2}$ emissions from Crystal Geyser, Utah. UCRL-TR-211870, Lawrence Livermore National Lab., Livermore, CA (USA).

Gratier, J.P. et al., 2012, How travertine veins grow from top to bottom and lift the rocks above them: The effect of crystallization force. Geology, v. 40, no.11, p. 1015-1018.

Han, W. et al., 2013, Characteristics of $\mathrm{CO}_{2}$-driven cold-water geyser, Crystal Geyser in Utah: experimental observation and mechanism analyses. Geofluids.

Haneberg, W.C., 2008, Using close range terrestrial digital photogrammetry for 3-D rock slope modeling and discontinuity mapping in the United States: Bulletin of Engineering Geology and the Environment, v. 67, no. 4, p. 457-469 (doi: 10.1007/s10064-008-0157-y).

Heath, J., 2004, Hydrogeochemical characterization of leaking carbon dioxide-charged fault zones in EastCentral Utah, Utah State University, USA.

Hintze, L. F., Willis, G. C., Laes, D. Y. M., Sprinkel, D. A., and Brown, K. D., 2000, Digital Geologic Map of Utah: Utah Geological Survey Digital State Map 179DM.

Johansen, T. E. S., and Fossen, H., 2008, Internal geometry of fault damage zones in interbedded siliciclastic sediments, in Wibberly, C. A. J., Kurz, W., Imber, J., Holdsworth, R. E., and Collettini, C., Editors, The internal structure of fault zones-Implications for mechanical and fluid-flow properties. Geological Society Special Publication v. 299, p. 35-56.

Kampman, N., Bickle, M., Becker, J., Assayag, N., Chapman, H., 2009, Feldspar dissolution kinetics and Gibbs Free Energy Dependence in a $\mathrm{CO}_{2}$-enriched groundwater system, Green River, Utah. Earth and Planetary Science Letters, v.284, no. 3-4, p. 473-488.

Kampman, N. et al., 2012, Pulses of carbon dioxide emissions from Intracrustal faults following climatic warming. Nature Geoscience, v. 5, no. 5, p. 352-358.

Knauss, K., Johnson, J., Steefel, C., 2005, Evaluation of the impact of $\mathrm{CO}_{2}$, co-contaminant gas, aqueous fluid and reservoir rock interactions on the geologic sequestration $\mathrm{Of} \mathrm{CO}_{2}$. Chemical Geology, v. 217 , no. 3-4, p. 339-350.

Knipe, R.J., 1993, The influence of fault zone processes and diagenesis on fluid flow, SG: 36 Diagenesis and Basin Development. American Association of Petroleum Geologist, Oklahoma City.

Krantz, R. W., 1988, Multiple fault sets and three-dimensional strain-Theory and Application: Journal of Structural Geology, v. 10, no. 3, p. 225-237.

Larsen, B., A. Gudmundsson, I. Grunnaleite, G. Sælen, M. R. Talbot, and S. J. Buckle, 2010, Effects of sedimentary interfaces on fracture pattern, linkage, and cluster formation In peritidal carbonate rocks: Marine and Petroleum Geology, v. 27, no. 7, p. 1531-1550. 
Mountney, N.P., Jagger, A., 2004, Stratigraphic evolution of an aeolian erg margin system: the Permian Cedar Mesa Sandstone, SE Utah, USA. Sedimentology, v. 51, p. 713-743.

O'Sullivan, R.B., 1981, The Middle Jurassic San Rafael Group and related rocks in east-central Utah. New Mexico Geological Society Guidebook, v. 32, p. 89-95.

Peterson, F., Turner-Peterson, C., 1989, Geology of the Colorado Plateau: Grand Junction to Denver, Colorado June 30-July 7, 1989, American Geophysical Union, v. 130.

Petrie, E.S., Barton, D. C., and Evans, J.P., 2013, Tectonic history and distribution of faults and fractures in the San Rafael Swell, impacts on subsurface fluid flow. in, The San Rafael Swell and the Henry Mountains Basin. Utah Geological Association Publication 42, in press.

Petrie, E. S., Jeppson, T. N., and Evans, J. P., 2012, Predicting rock strength variability across stratigraphic interfaces in caprock lithologies at depth-Correlation between outcrop and subsurface: Environmental Geosciences, v. 19, no. 4, p. 125-142.

Pickett, G. R., 1963, Acoustic character logs and their applications in formation evaluation: Journal of Petroleum Technology, v. 15, no. 6, p. 650-667.

Shipton, Z., Evans, J.P., Dockril,B., Heath, J.E., Williams, A., Kirschner, D., Kolesar, P.T., 2005, Natural leaking $\mathrm{CO}_{2}$-charged systems as analogs for failed geologic storage reservoirs, The $\mathrm{CO}_{2}$ Capture and Storage Project (CCP) II, Elsevier Science, p. 679-701.

Shipton, Z. et al., 2004, Analysis of $\mathrm{CO}_{2}$ leakage through 'low-permeability' faults from natural reservoirs in the Colorado Plateau, east-central Utah. Geological Society London Special Pub., v. 233, p. 43-58.

Shipton, Z. K., and Cowie, P. A., 2003, A conceptual model for the origin of fault damage zone structures in high-porosity sandstone: Journal of Structural Geology, v. 25, p. 333-344.

Shipton, Z.K., Evans, J. P., Robeson, K. R., Forster, C. B., and Snelgrove, S., 2002, Structural heterogeneity and permeability in faulted eolian sandstone: Implications for subsurface modeling of faults: American Association of Petroleum Geologist Bulletin, v. 86, no. 5, p. 863-883.

White, A., Brantley, S., 2003, The effect of time on the weathering of silicate minerals: why do weathering rates differ in the laboratory and field? Chemical Geology, v. 202, no. 3-4, p. 479-506.

Wenk, H.R.,Bulakh, A., 2004, Minerals. Their constitution and origin, Cambridge Univ. Press, Cambridge, p. 646.

Wigley, M., Dubacq, B., Kampman, N., Bickle, M., 2013a, Controls of sluggish, $\mathrm{CO}_{2}$-promoted, hematite and K-feldspar dissolution kinetics in sandstones. Earth Plan. Science Letters, v. 362, p. 76-87.

Wigley, M., Kampman, N., Chapman, H., Dubacq, B., Bickle, M., 2013b, In-situ re-deposition of trace metals mobilized by $\mathrm{CO}_{2}$-charged fluids. Geochemistry, Geophysics, Geosystems (G^3), v. 14. 
Wigley, M., Kampman, N., Dubacq, B., Bickle, M., 2012, Fluid-mineral reactions and trace metal mobilization in an exhumed natural $\mathrm{CO}_{2}$ reservoir, Green River, Utah. Geology, v. 40, no. 6, p. 555-558.

Wilkinson, M., Gilfillan, S.V.M., Haszeldine, R.S., Ballentine, C.J., 2009, Plumbing the depths: Testing natural tracers of subsurface $\mathrm{CO}_{2}$ origin and migration, Utah. In: Grobe, M., Pashin, J.C., Dodge, R.L. (Eds.), Carbon dioxide sequestration in geological media - State of the science. AAPG Studies in Geology, v. 59, p. 619-634.

Witkind, I. J., 1988, Geologic map of the Huntington 30' X 60' quadrangle, Carbon, Emery, Grand, and Uinta Counties, Utah: U.S. Geological Survey map I-1764.

\section{Publications/ Thesis, and Presentations}

\section{Theses and Dissertation}

Barton, D. C., 2011, Determining $\mathrm{CO}_{2}$ Potential: Characterization of Seal Integrity and Reservoir Failure in Exposed Analogs, M. S. Thesis, $173 \mathrm{pp}$.

Flores, S. L., in prep.,

Richey, D., in prep., Architecture and spatial variations of fault zone structure with implications for fault permeability and fluid migration pathways: An outcrop analysis of the Iron Wash fault, southeastern Utah, M. S. thesis, Utah State University.

Petrie, E. S., in prep. Rock strength of cap rock lithologies: evidence for past seal failure, migration of fluids and the analysis of the reservoir-seal interface in outcrop and the subsurface.

The last three students all will defend their theses in the summer or early fall of 2013, and complete in 2013.

\section{Publications}

Petrie, E. S., Jeppson, T. N., Evans, J. P., 2012, Predicting rock strength variability at stratigraphic interfaces in caprock lithologies at depth: correlation between outcrop and subsurface, in: Environmental Geoscience. 19(4): 125-142.

Petrie, E. S., D. C. Barton, and J.P. Evans: Tectonic History And Distribution of Faults and Fractures in the San Rafael Swell, Utah: Impacts on Subsurface Fluid Flow, Utah Geological Association 2013 Guidebook.

Petrie, E. S., Petrie, R. A. and Evans, J. P., in press, pending final revisions, Identification of reactivation features and increased permeability associated with a fault damage zone using UV-induced fluorescence, submitted to Journal of Structural Geology, March 2013.

Petrie, E. S., and Evans, J. P., submitted, Failure of cap rock seals as determined from mechanical stratigraphy and stress history of exhumed analogs, to: Am. Assoc. Petroleum Geol. Bulletin.

Petrie, E. S., Bauer, S. J., and Evans, J. P., Mechanical properties of reservoir - caprock interfaces.

Richey, D., 2013, The Iron Wash Fault: natural example of seal bypass faulting; to Utah Geological Association 2013 Guidebook.

\section{Presentations/Abstracts}

Flores, S. L., and Evans, J. P., 2013, Natural fracture systems near the Jurassic/Carmel contact along the east flank of the San Rafael Swell, Utah: Analogs for seal bypass at a reservoir-seal interface, Geo. Soc. Am. 2013 meeting,

Giles, N.S., and Evans, J.P., 2011. The effects of $\mathrm{CO}_{2}$ flow within proposed sequestration lithologies, 
Geological Society of America Abstracts with Programs, Vol. 43, No. 4, p. 50.

Petrie, E.S., Evans, J.P., and Jeppson, T.N., 2011, Fracture behavior across interfaces, American Geophysical Union Meeting Abstract V13E-01, Dec. 2011.

Petrie, E.S., Jeppson, T., and Evans, J.P., 2011. Use of wireline logs for identification of rock strength variability in caprock lithologies, Geological Society of America Abstracts Prog, Vol. 43, No. 4, p. 81.

Petrie, E. S., Evans, J. P., 2013. Mechanical stratigraphy and stress history of cap-rocks - analysis of exhume analogs in SE Utah and implications for CCS. RM-AAPG, Salt Lake City, 2013.

Petrie, E. S., Evans, J. P., 2013. Modeling the significance of mechanical interfaces to fracture propagation and morphology - geomechanical models derived from outcrop analysis. Unconventional Resources Technology conference, Denver, CO 2013.

Petrie, E. S., Evans, J. P., 2012. Comparison between Mechanical and Fracture Stratigraphy between Failed Seal Analogues. European Association of Geoscientist and Engineers, Montpellier, France.

Petrie, E. S., Evans, J. P., 2010. Use of Wireline Logs to Estimate Strength of Cap Rock. Lithologies. American Geophysical Union, Meeting Abstracts. Abstract no. MR11B-1878.

\section{Education/Students}

Student success in this research group was fostered by a collaborative approach. The PI outlined broad project objectives, developed resources for successful implementation, and guided students in their research. Individual students were empowered to develop their own research plans (within project goals), conduct research independently in the field or laboratory, and communicate with fellow students, Evans, and the scientific community via posters/ talks at professional meetings.

- Corey Barton completed his MS in December 2011

- Santiago Flores will finish his MS in Fall 2013

- PhD student Elizabeth Petrie is on track to complete her PhD dissertation by Sept 2013

Petrie also attended a 10-day Research Experience in Carbon Sequestration short course, held in Birmingham, AL, [sponsored by NETL and SECARB] and presented an invited talk at the American Geophysical Union (2011).

In addition to graduate-level work, the study provided opportunities for innovative undergraduate research. Nathan Giles completed a senior thesis and he has designed a new experimental apparatus (described under lab methods), as well as a field helicopter. Undergraduates who have helped in the field include Brennan Young and Rebekah Wood.

We hosted Dr. Alvar Braathen, a sabbatical visitor from UNIS, Svalbard, Norway, from June 2010 to June 2011, who is involved in several Norwegian $\mathrm{CO}_{2}$ capture and storage projects in rocks. We also hosted the director of UNIS, Dr. Gunnar Sand, and discussed further collaborations.

In May 2011, using Braathan's Fulbright funding, we held a field trip and informal seminar on $\mathrm{CO}_{2}$, fluid-rock interactions, and rock deformation based in Moab, Utah. Approximately six faculty and post-doc researchers and 15 graduate students from Utah, New Mexico, Norway and France attended. The seminar was held at the USU Moab educational center. 